ISSN: 0213-2079 - ISSN electrónico: 2386-3889

DOI: https://doi.org/10.14201/shhmo2019412303338

\title{
LAS COSAS DEL COMER. EVOLUCIÓN DEL GASTO ALIMENTICIO EN UN CONVENTO RURAL DE BIZKAIA, $(1585-1825)^{*}$
}

\section{Evolution of food expenditure patterns in a Biscayan rural convent, (1585-1825)}

\author{
Elena CATALÁN MARTÍNEZ \\ Universidad del País Vasco \\ Correo-e: elena.catalan@ehu.eus \\ orcid: 0000-0002-0033-9157
}

Fecha de recepción: 16 de julio de 2018

Fecha de aceptación: 8 de mayo de 2019

RESUMEN: El convento de la Merced de Markina (Bizkaia) conserva sus libros de cuentas por un periodo cronológico excepcionalmente extenso (1590-1825), con el interés añadido de que está ubicado en una zona rural. El análisis del gasto ordinario, especialmente en alimentación, ha permitido establecer la variación del mismo en el largo plazo y su ajuste a las diferentes coyunturas económicas por las que atravesó el convento. Sin embargo, solo durante la etapa expansiva de la segunda mitad del XVIII consiguieron mantener una dieta similar a la de otros conventos del área cantábrica.

Palabras clave: monjas; consumo alimenticio; gestión convento; rentas; orden de la Merced.

* Este trabajo ha sido posible gracias al Ministerio de Economía y Competitividad, que ha financiado el proyecto HAR2014-52434-C5-5-P, y también al Departamento de Educación, Universidades e Investigación del Gobierno Vasco, dentro del Programa de Financiación a Grupos de Investigación del Sistema Universitario Vasco, IT897-16.

Ediciones Universidad de Salamanca / @@ Stud. his., H. ${ }^{a}$ mod., 41, n. 2 (2019), pp. 303-338 
ABSTRACT: The convent of The Merced of Markina (Bizkaia), preserves their books of general expenses for an exceptionally wide period (1585-1830) and has added interest due to its rural location. The analysis of the alimentary consume patterns has allowed us to establish the variation on said patterns in the long run and its adjustment to the different economic situations that the convent went through. However, only in the expansive situation of the second half of the XVIII century they were able to maintain a similar diet to other convents in the Cantabrian area.

Keywords: nuns; food consumption: convent management; income; order of Mercy.

\section{INTRODUCCIÓN}

En los últimos años, el debate en torno a la «Pequeña Divergencia» en el contexto europeo está propiciando una renovación historiográfica que busca definir los niveles de vida durante la Edad Moderna más allá de la mera cuantificación de precios y salarios. Así, se ha prestado especial atención a la composición de canastas de consumo en las que se tiene en cuenta un amplio abanico de bienes y servicios demandados por la población, atendiendo a la especificidad derivada de la pertenencia a un determinado grupo social y sus variaciones a lo largo del tiempo ${ }^{1}$. A pesar de que para su elaboración se han utilizado contabilidades de instituciones religiosas, apenas se han establecido patrones de consumo que tengan en cuenta las diferencias interestamentales en lo que se refiere a la cantidad y la calidad de los productos ingeridos.

En el caso del clero, existe una tendencia unificar los patrones procedentes de cabildos catedralicios o grandes monasterios al conjunto del estamento, sin tener en cuenta su heterogeneidad. Sin embargo, para analizar el mundo eclesiástico en toda su complejidad, se debería diferenciar entre clero secular y clero regular, entre el mundo urbano y el mundo rural, y entre las distintas órdenes religiosas. Así mismo, no se puede obviar el hecho de que la viabilidad y bienestar de una comunidad no solo dependerá de sus rentas y de las variaciones coyunturales, sino de la correcta administración que se haga de ellas. En este sentido, es necesario acometer estudios de caso de carácter regional que contemplen toda la diversidad del estamento eclesiástico

1. Para Madrid cabe destacar los trabajos de Ringrose, 1985; LLopis y García-Montero, 2011; Andrés y Lanza, 2014; Calderón, García-Montero y LLopis, 2017; para Sevilla, GonzálezMariscal, 2015; para Toledo, González-Agudo, 2016; para Barcelona, Feliú, 2004; para Santander, Lanza, 1991.

Ediciones Universidad de Salamanca / అ@@ Stud. his., H. ${ }^{a}$ mod., 41, n. 2 (2019), pp. 303-338 
con el fin de poder establecer estándares en las pautas de consumo, así como la capacidad de estas instituciones de adecuar sus gastos a las variaciones de sus ingresos.

En un principio, este trabajo se planteó como un estudio de caso que permitiera elaborar una cesta de la compra básica para un convento rural situado en la zona atlántica y sus variaciones en el largo plazo. El objetivo no era otro que aportar datos sobre su composición y cuantía, con el fin de facilitar futuros análisis comparativos con otras instituciones religiosas y con la población del entorno. Para ello se recurrió a una fuente clásica en estos casos: los libros de gasto diario de un convento de monjas mercedarias situado en una villa, Markina-Xemein (Bizkaia), con funciones propias de una cabecera de comarca y una economía basada en actividades agropecuarias e industriales - carboneo y siderurgia $-{ }^{2}$. Este hecho, a priori, era sumamente sugestivo puesto que la mayoría de los conventos se localizaron en entornos urbanos con unas características socioeconómicas sustancialmente diferentes. Además, el extenso arco cronológico que abarcaban sus cuentas $(1584-1825)^{3}$ permitía realizar un análisis en el largo plazo, cosa poco frecuente en análisis de este tipo.

Sin embargo, la fuente prometía más de lo que ha sido capaz de dar de sí. En primer lugar, la forma de contabilizar determinados productos varía a lo largo del periodo analizado, lo que origina serios problemas de metrología, siendo la mayoría de las veces muy difícil establecer un cálculo realista de consumo sin recurrir a la distorsión estadística de los datos. En segundo lugar, ha resultado imposible determinar el número exacto de personas que componían la comunidad, cuántas comían diariamente en el convento y si todas tenían acceso al mismo tipo de alimentos. No existe un listado en el que conste el número de profesas, novicias o criadas para la totalidad del arco cronológico contemplado. Tan sólo disponemos de datos en momentos puntuales, las referencias derivadas de la compra de las «faltas de pan» para la segunda mitad del siglo XVII, y de las bulas adquiridas para monjas y criadas para el XVIII. Las lagunas se han completado efectuando un cálculo a partir de las defunciones y profesiones. Aun dando como válida esta estimación, no se puede establecer un consumo per cápita ya que existen evidencias de que en los conventos existía un sesgo socioeconómico en el acceso a cierto tipo de bienes ${ }^{4}$. Sabemos que

2. Aunque Markina era una villa en el ordenamiento jurídico del Señorío de Bizkaia, no se la puede considerar como un entorno urbano ni por sus dimensiones ni por su actividad económica. En el siglo XVIII, el censo de Floridablanca cifraba su población en 2.092 habitantes.

3. Archivo de las Mercedarias Misioneras de Berriz/España [ES/AMMB], Fondo de Markina [AM], Libros de Gastos y recibos: 1584-1605: AM-0003/004-00; 1616-1648: AM-0011/001-00; 1649-1692: AM-000/002-00; 1692-1747: AM-0011/002-00; 1747-1830: AM-0012/001-00. En adelante: AMMB-AM Libros de gastos y de recibos.

4. En este sentido, el trabajo de Burgo López (1987), ofrece diferentes raciones anuales en función de la jerarquía social que rige en el monasterio de San Payo de Antealtares (Galicia).

Ediciones Universidad de Salamanca / @®@@ Stud. his., H. ${ }^{a}$ mod., 41, n. 2 (2019), pp. 303-338 
las novicias pagaban una cantidad variable en concepto de «alimentos», lo que daba derecho a una ración básica de legumbre, aceite, tocino y sidra. El pescado de las vigilias, el cabrito cuando se encontraban enfermas, o cualquier extra que pudieran efectuar se contabilizaba aparte. La manutención también formaba parte de los salarios de criadas, peritos, trabajadores agrícolas y de la construcción, aunque nada sabemos de su composición o importe. Cabe suponer que, al menos en el siglo XVIII, debieron tener un impacto grande en el presupuesto general habida cuenta de que se acometieron obras de acondicionamiento tanto del convento como de las tierras y caserías recién adquiridas. Por último, habría que añadir los agasajos para provinciales y visitas destacadas que incluían las mejores viandas como muestra de hospitalidad y cortesía.

Todas estas circunstancias imposibilitan la estimación de la ingesta diaria per cápita $\mathrm{y}$, por lo tanto, de un balance nutricional equiparable a los realizados para otros estratos sociales. A pesar de no cumplir con las expectativas iniciales, los libros de cuentas ofrecen una valiosa información sobre el tipo de productos que entraban en la despensa del convento procedentes del mercado. El análisis de su composición y variaciones en el largo plazo puede contribuir a completar los estudios de alimentación y condiciones de vida en la España Moderna. Asimismo, se puede inferir cuáles fueron los mecanismos de ajuste del gasto ante las diferentes coyunturas económicas, mostrando una imagen nítida del funcionamiento económico de las economías conventuales femeninas.

A lo largo de este trabajo se intentará definir la estructura del gasto ordinario del convento de la Merced de Markina, prestando especial atención a la composición de los alimentos, y sus variaciones a lo largo de los siglos XVII y XVIII. Para ello, el texto se ha estructurado en tres apartados. En el primero se realiza un breve repaso a las diferentes coyunturas económicas por las que atravesó el convento, imprescindibles para poder contextualizar la evolución de cada una de las partidas de gasto. En el segundo, se analizará su estructura, prestando especial atención a la composición de lo que se ha denominado «vida cotidiana». En el tercero, se desglosarán las partidas destinadas a la alimentación, utilizando, siempre que ha sido posible, las cantidades compradas por monja a modo de proxi de consumo. En este sentido, se pretende poner en valor lo que suponía para cada integrante de pleno derecho de la comunidad la compra de productos básicos destinados al mantenimiento diario del convento y sus actividades.

\section{EVOLUCIÓN DE LA ECONOMÍA DEL CONVENTO DE LA MERCED DE MARKINA}

Normalmente se ha ofrecido una visión muy inmovilista de la gestión económica de los conventos femeninos. En ella, las decisiones económicas de las monjas 
aparecen supeditadas a las directrices de los Provinciales de cada orden, quienes ejercían el control a través visitas trianuales y el nombramiento de un administrador que las representaba en no pocas transacciones. Sin embargo, el análisis de la contabilidad revela una gran autonomía de gestión, especialmente en lo referente al cobro de réditos de los censos consignativos y al abastecimiento de bienes de primera necesidad.

Desde finales del XVI y durante todo el XVII, cada partida presupuestaria tenía asignada una determinada renta, sin que se produjeran trasvases entre ellas en caso de descubiertos. Las previsiones de gasto se realizaban teniendo en cuenta el número de monjas y las necesidades diarias de cada una de ellas. Este cálculo solo afectaba a las profesas ya que eran las únicas que habían hecho efectivo el importe de su dote, garantizando así de por vida su sustento y su contribución al mantenimiento del convento. El resto de las habitantes del convento - novicias o huéspedes - debían abonar tanto el importe de los alimentos consumidos como el coste del culto ya que no tenían derecho a participar en el acervo común precisamente por no haber pagado su dote. Esta dinámica explica la preferencia de inversión hacia activos que devengaran una renta fija anual - censos y juros - sobre otras opciones más expuestas a las variaciones coyunturales. Sin embargo, a partir del siglo XVIII, la inversión en censos y juros fue sustituida por la compra de bienes inmuebles para explotarlos bajo régimen de arrendamiento ${ }^{5}$. La lógica del mercado se fue imponiendo en las economías conventuales, buscando la rentabilidad de sus inversiones y la gestión del patrimonio de manera global, sin asignar ningún ingreso concreto a determinados gastos.

Grosso modo, se pueden establecer cinco grandes periodos en la vida económica de este convento (gráfico 1).

El primero, entre 1545 y 1624, corresponde a su etapa como beaterio y estuvo marcado por las limitaciones económicas que impuso la familia fundadora, la casa Bidarte, llegando a comprometer seriamente su viabilidad. El codicilio testamentario establecía una renta anual de 50 fanegas de trigo que en principio debían ser suficientes para satisfacer las necesidades de 10 monjas, máximo permitido por la fundación. Asimismo, se especificaba que cualquier incremento de capital procedente de dotes o donaciones debía invertirse en «tierra para huertos y manzanales e mas tierra de 150 pies de castaños, un robledal que se pueda cortar en cada cortadura hasta 100 cargas de carbón para leña», señalando en 30.000 maravedís y 100 fanegas de trigo la renta máxima acumulable ${ }^{6}$.

5. Este comportamiento ha sido constatado para Andalucía por López Martínez, 1992 y 1995; para Aragón por Atienza 1991; en Madrid por Soriano, 1994 y 2000.

6. Cédula de fundación del beaterio del convento de Markina. 05-08-1547. [ES/AMMB/ F06.00.00 (AM-0008/002-01)]. 
ELENA CATALÁN MARTÍNEZ

LAS COSAS DEL COMER. EVOLUCIÓN DEL GASTO ALIMENTICIO

EN UN CONVENTO RURAL DE BIZKAIA, (1585-1825)

\section{Gráfico 1}

Estructura del ingreso del ingreso y número de monjas

Nuestra Señora de la Merced de Markina, 1584-1825

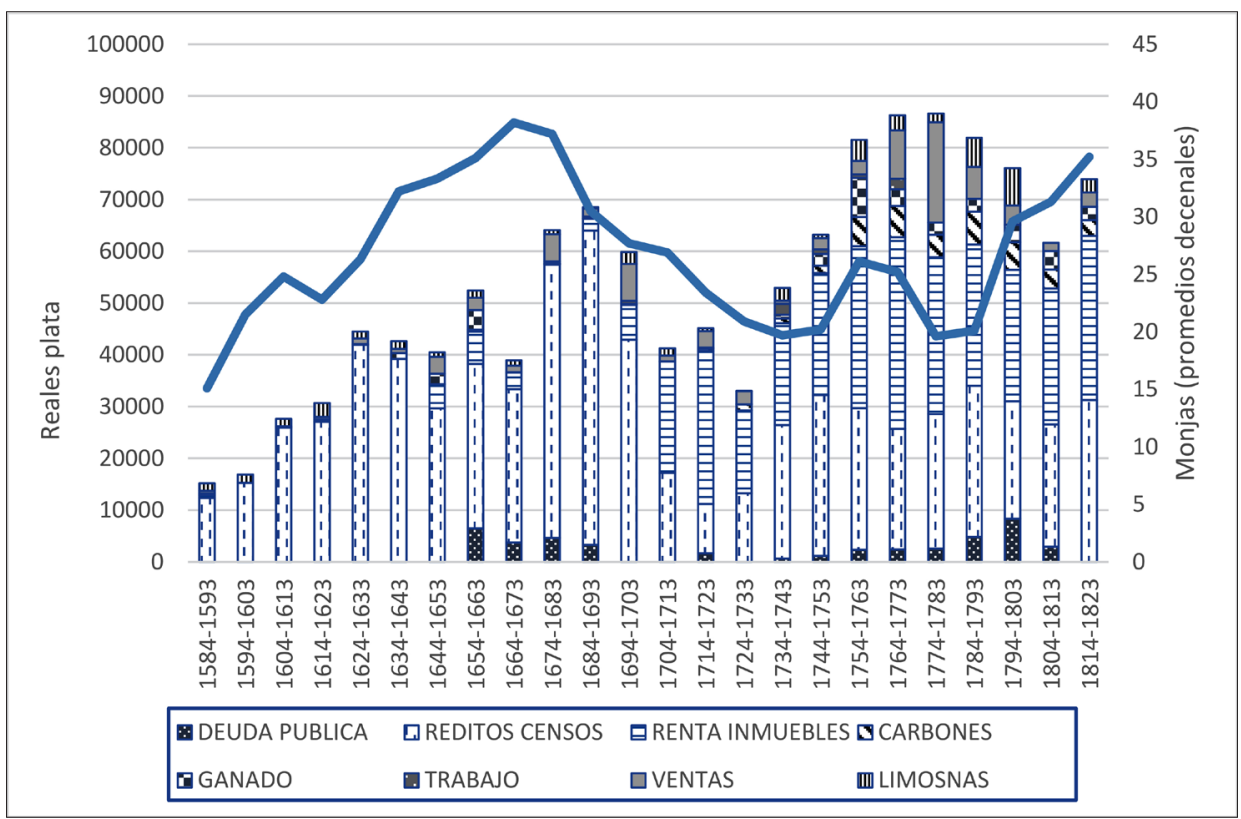

Fuente: Elaboración propia. AMMB-AM Libros de gastos y de recibos.

La obligatoriedad de guardar clausura para los establecimientos femeninos, impuesta en Trento, obligó a buscar los medios que garantizaran su supervivencia económica. La búsqueda de un benefactor que aportase una renta fue la solución más frecuente. Sin embargo, la viabilidad cualquier convento pasaba por el incremento de postulantes y el pago de sus respectivas dotes. En el caso de Markina se iniciaron las negociaciones con la familia fundadora para que se modificasen las cláusulas testamentarias, en especial las relativas al número máximo permitido de monjas y a las limitaciones de renta. La reiterada negativa por parte de esta a modificarlas provocó que las monjas aceptasen nuevas novicias cuyas dotes invertían en censos, a pesar de la prohibición expresa de hacerlo. En contrapartida, la casa Bidarte suspendió el pago de la dotación mientras no respetasen las condiciones de la fundación. La ruptura definitiva se consumó en 1623 al trasladarse las monjas a otro emplazamiento intramuros de la villa y adoptar la clausura. Este hecho tuvo consecuencias económicas muy graves ya que perdieron, además de la dotación de trigo anual, todas las tierras y bosques que habían sido adquiridos con las dotes y

Ediciones Universidad de Salamanca / 요 Stud. his., H. ${ }^{a}$ mod., 41, n. 2 (2019), pp. 303-338 
que legalmente eran propiedad de la familia Bidarte. Esta situación de inestabilidad se refleja en un ajuste necesario de los gastos cotidianos, adoptando una postura muy conservadora en el cálculo de sus necesidades en la que se asignaba un máximo diario por monja de 2,5 reales de vellón destinado a cubrir sus necesidades básicas.

Una vez liberadas de la tutela de los Bidarte el convento comenzó una etapa claramente expansiva (1630-1680), confirmando la tendencia europea de auge de las economías monásticas en una coyuntura general recesiva (Landi, 2004:39). Durante este periodo, el número de profesiones no dejó de crecer alcanzándose el máximo de ocupación del convento en 1673 con 40 monjas. Las dotes continuaron invirtiéndose en censos consignativos, consolidando el perfil prestamista de la institución, aunque también se admitió, como pago de estas, juros y el derecho de explotación de bosques, tierras y ganado por un tiempo limitado, normalmente hasta que la familia de la novicia hubiera saldado la deuda ${ }^{7}$. Este proceder explica que en la contabilidad del convento aparezcan partidas procedentes de la explotación de ganado o de la renta de unas tierras de las que realmente no eran propietarias. Entre 1642 y 1670, con motivo de la inflación del vellón, comenzaron a exigir el importe íntegro de la dote en metálico con al menos un tercio en moneda de plata cuyo premio se destinaba a la compra de trigo o a la imposición de nuevos censos. Las dificultades por parte de los censatarios para cumplir con sus obligaciones obligaron al convento a aceptar el pago de los réditos en varios plazos o en especie - leña, carbón, hierro, bueyes, vacas, etc. - que luego comercializaban o se quedaban para consumo interno. Todo ello les permitió ampliar el umbral mínimo de gasto por monja, aunque la adquisición de productos básicos - trigo, aceite, pescado, carne - siguió realizándose sobre unas previsiones bastante austeras.

Entre 1690 y 1730 (tercer periodo), la notable disminución de los ingresos ordinarios y la reducción del tipo de interés de los censos, afectó profundamente a la capacidad económica del convento, lo que le llevó a pedir préstamos por un total de 18.392 reales de vellón -el 48,5 por 100 en forma de censo-para hacer frente a la compra de trigo y a los gastos indispensables de la casa. Al parecer no fue suficiente puesto que solicitaron varios permisos al provincial para utilizar con el mismo fin el dinero de las dotes, legítimas y las escasas redenciones que se habían producido. Los concursos de acreedores se multiplicaron y, con frecuencia, los bienes concursados no alcanzaron para cubrir la deuda, dadas las condiciones de deterioro en que se encontraban. Este momento recesivo coincidió también con una brusca

7. En el libro de gastos e ingresos correspondiente al periodo 1616-1648 [AMMB- AM 011/001-00] abundan ejemplos de este proceder. Por citar solo uno, tenemos el caso de Marín Pérez de Abaitua que cedió la explotación y crianza de varias cabezas de ganado por un tiempo determinado hasta que se acabara de pagar la deuda contraída por su hija. La titularidad del ganado debía volver a la familia cuando esto sucediera.

Ediciones Universidad de Salamanca / @®@@ Stud. his., H. ${ }^{a}$ mod., 41, n. 2 (2019), pp. 303-338 
caída del número de vocaciones y por lo tanto de la capacidad de inversión de la institución. Ante esta situación se decidió apostar por invertir en mejorar el patrimonio raíz para poderlo vender o arrendar más fácilmente ${ }^{8}$. El convento recurrió al crédito para llevar a cabo obras de acondicionamiento y mejora de las fincas, como el drenaje de campos, cercamientos o mejora de los suelos con tratamientos de cal y estiércol. También cambiaron el uso de algunas parcelas desbrozando el terreno y preparándolo para la siembra o para plantar robles y castaños de uso carbonero. Se compraron bueyes, terneros y ovejas que explotarían en régimen de aparcería, y dotaron de nuevas piedras al molino?.

A partir de la década de 1740 se inicia el cuarto periodo en el que la renta de tierras, caserías, ganado y explotación del bosque habían sustituido casi por completo a la actividad crediticia, y lo poco que quedaba de esta había cambiado sustancialmente. Ahora se imponían pocos censos, pero con unos principales más abultados que suscribían, por norma general, los ayuntamientos ${ }^{10}$. Esta recuperación económica no fue acompañada por un aumento similar de las vocaciones. Lejos de constituir un hándicap, como sucedía en épocas anteriores, esta disminución de monjas permitió ampliar el umbral de gasto per cápita ya que la explotación de fincas rústicas garantizaba unos ingresos superiores a los obtenidos por el interés de los censos. Con mayor capacidad de compra y una oferta más diversificada, la cantidad adquirida de productos básicos se incrementó sustancialmente y aparecieron otros nuevos como el chocolate o el arroz.

La década de 1790, marcaría el fin de la época expansiva tanto por la reducción de los ingresos ordinarios como por un fuerte incremento del gasto. El traslado de las monjas del convento de mercedarias de Bilbao, que se refugiaron en el de Markina huyendo de la guerra contra la Convención, desestabilizó la economía de

8. «Hemos puesto cedulas de venta para toda la hazienda y nadie ha respirado; con que en llegando el tiempo procuraremos disponer nuevos arriendos de cassas y hacer los reparos que necesitaren porque si están derrotadas, además de ser principio de su perdición o no habrá quien las quiera arrendar o las quiera muy baratas». Carta de Manuel de Sandoval a Ma Teresa de san José, comendadora, fechada en Logroño a 11 de febrero de 1736. Correspondencia 1637-1820. [ES/AMMB/F06.00.00 (AM-020/002-01)].

9. En las cuentas tomadas en 1738 el visitador escribía: «En el trienio de 1735-1738 se han pagado todas las deudas y no se debe nada. Se han reparado las caserías de Ybarguen, Elorriaga, Yurre, Oronzua, casa del indiano, Ubegui Ziarreta, casa de Logroño y la hacienda de viñas que hay allí, con un coste de 1.729 reales» [ES/AMMB/F06.00.00 (AM-0012/001-00)].

10. Esta reorientación en la cesión de capitales hacia concejos y alta aristocracia fue común a la mayoría de los conventos de la península y duró hasta la última década del siglo XVIII en que la crisis finisecular volvió a activar el mercado del crédito entre particulares. Como ejemplo, véase Atienza, 1991:506-507. 
la comunidad al duplicarse el número de bocas a las que alimentar, en un momento de crisis económica y fuerte incremento de la presión fiscal ${ }^{11}$.

\section{ESTRUCTURA DEL GASTO DE DIARIO DEL CONVENTO DE LA MERCED DE MARKINA}

Los gastos del convento de la Merced de Markina son típicos de cualquier institución eclesiástica: el gasto básico para garantizar la «vida cotidiana»-alimentación, vestido, comida, vivienda, iluminación y combustible-; los derivados de su actividad religiosa - «culto»-; y, por último, los relativos a su condición de rentista — «administración» $-{ }^{12}$.

Tabla 1.

Estructura del gasto en porcentajes

Nuestra Señora de la Merced de Markina, 1585-1824

\begin{tabular}{|l|c|c|c|c|c|c|}
\hline & $\mathbf{1 5 8 5}$ & $\mathbf{1 6 2 5}$ & $\mathbf{1 6 5 5}$ & $\mathbf{1 7 0 5}$ & $\mathbf{1 7 5 5}$ & $\mathbf{1 7 9 5}$ \\
& $\mathbf{1 6 2 4}$ & $\mathbf{1 6 5 4}$ & $\mathbf{1 7 0 4}$ & $\mathbf{1 7 5 4}$ & $\mathbf{1 7 9 4}$ & $\mathbf{1 8 2 4}$ \\
\hline VIDA COTIDIANA* & $\mathbf{8 9 , 2}$ & $\mathbf{8 6 , 9}$ & $\mathbf{7 7 , 0}$ & $\mathbf{6 2 , 4}$ & $\mathbf{6 6 , 6}$ & $\mathbf{6 3 , 9}$ \\
\hline Alimentación & 91,6 & $\mathbf{7 4 , 6}$ & 87,7 & $\mathbf{7 9 , 0}$ & $\mathbf{7 0 , 3}$ & 57,2 \\
\hline Combustible e Iluminación & 0,5 & 1,1 & 8,8 & 6,0 & 6,0 & 11,1 \\
\hline Vivienda & 3,6 & 21,4 & 4,2 & 2,6 & 14,9 & 19,1 \\
\hline Textiles & 0,3 & 0,1 & 0,1 & 1,2 & 0,6 & 0,3 \\
\hline Menaje & 0,4 & 1,0 & 1,7 & 1,7 & 1,5 & 5,4 \\
\hline Servicios & 3,4 & 1,7 & $\mathbf{2 , 5}$ & 9,4 & 6,7 & 6,9 \\
\hline CULTO & $\mathbf{4 , 9}$ & $\mathbf{2 , 9}$ & $\mathbf{1 3 , 5}$ & $\mathbf{1 5 , 9}$ & $\mathbf{8 , 4}$ & $\mathbf{7 , 2}$ \\
\hline ADMINISTRACIÓN & $\mathbf{5 , 9}$ & 10,2 & $\mathbf{9 , 5}$ & $\mathbf{2 1 , 7}$ & $\mathbf{2 5 , 0}$ & $\mathbf{2 8 , 9}$ \\
\hline
\end{tabular}

Elaboración propia. AMMB-AM Libros de gastos y de recibos.

* Desglose de partidas realizados sobre el promedio de gasto total de «vida cotidiana»

11. Entre 1810 y 1814 el Señorío de Bizkaia impuso una contribución territorial que afectó sobre todo a las propiedades del clero. Además, la Guerra de Independencia provocó el hundimiento de la renta neta obtenida de sus explotaciones, llegando a ocasionar pérdidas.

12. Para el análisis de los gastos, se ha procedido a una distribución temporal de 50 años, excepto en la primera mitad del siglo XVII que ha dividido en dos etapas marcadas por el traslado de ubicación, la clausura y su ruptura con la casa de Bidarte. El último periodo viene definido por el inicio del ciclo bélico y las primeras reformas liberales.

Ediciones Universidad de Salamanca / అ@@ Stud. his., H. ${ }^{a}$ mod., 41, n. 2 (2019), pp. 303-338 
Como se observa en la Tabla 1, el apartado de «vida cotidiana» ocupa la mayor parte del presupuesto del convento, aunque su peso porcentual va disminuyendo a medida que se incrementan las partidas correspondientes al mantenimiento del culto y a la administración de bienes inmuebles. Desglosando su contenido, se puede afirmar que el principal desembolso correspondió a la alimentación, aunque su peso porcentual fue descendiendo a medida que se incrementaba la capacidad adquisitiva del convento ${ }^{13}$. Su composición y evolución se desglosará con detalle en el punto 3.

Tras la alimentación, el combustible e iluminación constituyen el segundo gran apartado presupuestario, incrementado por las necesidades de culto e iluminación de la iglesia. La cera de abeja solo se utilizaba con fines litúrgicos por su alto coste. Para las luminarias de la casa se prefirió el aceite de oliva, aunque a partir de la segunda mitad del siglo XVII, el sebo iría ganando terreno por su menor precio y mayor accesibilidad. En 1668, el saín viene a ampliar la oferta de productos lumínicos, aunque solo sería competitivo en precio durante un breve periodo de tiempo ya que en la década de 1740 su precio superaba con mucho al del aceite o el sebo ${ }^{14}$. El último tercio del siglo XVIII fue testigo de un cambio en el patrón de consumo lumínico al ir sustituyéndose de forma paulatina el sebo por las velas de cera. Se trata sin duda de un salto cualitativo ya que la cera sufrió una enorme variación de precios a partir de la abolición de la tasa que le llevó a duplicar su valor en relación al periodo anterior ${ }^{15}$.

Con respecto al combustible, el convento consumió preferentemente leña que se adquiría junto a gavilla, helechos u hojarasca, y paja para su uso en las cuadras ${ }^{16}$. Hasta la segunda mitad del siglo XVII, apenas se registran entradas específicas de leña, aunque sí aparecen partidas destinadas a pagar su trasporte. Es más que probable que el convento se abasteciera de los bosques propiedad primero del patrón y, más tarde, de la propia institución. Esta situación cambió a partir de la década de

13. De esta manera se cumple la Ley de Engel que indica que a medida que la renta va aumentando, los gastos que se dedican al consumo de artículos aumentan también, pero en distinta proporción: en los de primera necesidad los gastos son decrecientes, mientras que en los bienes de lujo relativo y de lujo propiamente dicho los gastos son crecientes. Los presupuestos familiares que se han elaborado para finales del siglo XVIII en un entorno urbano ofrecen un peso similar para la alimentación en el conjunto del gasto (Bernardos, 2004a: 279; Llopis y García-Montero, 2011: 298).

14. En el periodo comprendido entre 1735 y 1759 , el precio medio pagado por el convento por la libra de aceite de ballena era de 1,67 reales frente a los 1,53 reales por libra del aceite o los 1,20 del sebo [AMMB-AM 0011/002-00; AMMB-AM 0012/001-00)].

15. Durante el siglo XVIII, el precio medio de la libra de cera se mantuvo en torno a los 8 reales y medio mientras que durante el periodo comprendido entre 1810 y 1824 el promedio se situó en torno a los 16 reales [AMMB-AM 0012/001-00)].

16. La gavilla (sarmientos, ramas, hojas, etc.) se utilizaba para encender el hogar y, en muchas partidas, aparece contabilizada junto con paja y helechos. Por esta razón se han incluido en combustible e iluminación, aunque se utilicen en las cuadras.

Ediciones Universidad de Salamanca / @®@@ Stud. his., H. ${ }^{a}$ mod., 41, n. 2 (2019), pp. 303-338 
1670, cuando se regularizan las compras incrementándose el desembolso medio por monja y, en consecuencia, su importancia relativa en el apartado de combustible e iluminación ${ }^{17}$. Por su parte, el carbón vegetal tuvo una presencia testimonial ya que solo se utilizó para complementar el salario del vicario y de las músicas ${ }^{18}$. A partir de la década de 1760, pasó a formar parte del gasto ordinario en sustitución de la leña que estaba experimentando un fuerte incremento en su precio ${ }^{19}$.

La vivienda es otro concepto importante en cualquier presupuesto y venía a suponer a finales del siglo XVIII, dependiendo del tamaño y ubicación del inmueble, entre el 10 o 12 por 100 del gasto en una familia de artesanos madrileña (Llopis y García-Montero, 2011: 298) ${ }^{20}$. En el caso de las instituciones eclesiásticas, este apartado estaba compuesto primero por los costes de construcción del edificio, momento en el que se realizaba una fuerte inversión, y más tarde de los derivados de su mantenimiento. Esto originaba que las partidas destinadas a este fin sufrieran una gran volatilidad, alternando periodos de fuerte desembolso - como los que coinciden con la construcción o ampliación del convento - con otros de menor intensidad, en los que simplemente se acometen reparaciones puntuales del edificio.

Mención aparte merece el equipamiento de la vivienda. Camas, sillas, mesas, armarios o menaje del hogar - cacerolas, pucheros, sartenes, escobas, barreños, tinajas, cestas o braseros - eran de factura sencilla, tal y como corresponde a la austeridad que se debía guardar en un convento reformado. Sin duda, estos enseres se parecían mucho más a los que utilizaban sus convecinos que a los del clero diocesano o las clases más acomodadas. Las monjas también consumieron libros, papel, tinta, cuerdas para las arpas o productos de tocador, como el agua de azahar, de manera ocasional.

17. Es imposible calcular los kilos $/ \mathrm{m}^{3}$ que consume el convento ya que la leña viene expresada en carros y cargas. Al no saber de qué especie arbórea procede, si se vende en seco o verde, no se puede determinar su densidad y, por lo tanto, su peso exacto. Por otra parte, la medida de un carro puede variar mucho en lugares muy próximos entre si (Uriarte, 1988:94:125126 y Ceballos, 2001:96).

18. Todos los conventos mercedarios tenían instituida una renta a modo de capellanía para dotar a una o dos monjas para que tocaran el órgano y el arpa.

19. El precio medio de la carga de leña pagada por el convento durante el periodo de 1705-1754 fue de 2,6 reales; entre 1755-1794 el precio medio había ascendido hasta los 4,09 reales y a 8,8 reales entre 1795-1824 [AMMB-AM 0011/002-00: AM 0012/001-00)].

20. Recientemente, se está concediendo gran importancia a la variación de los precios de la vivienda en la composición de las canastas de consumo básico, puesto que es una partida sujeta a una gran volatilidad, como ha demostrado González-Mariscal (2015:3) para la Sevilla del siglo XVI. Además de las alteraciones del precio del alquiler a lo largo de la Edad Moderna, se debe tener en cuenta la optimización del espacio y la división en altura que consagra una estratificación social en función de la altura y, por lo tanto, el alquiler también varía según la planta del edificio del que se trate (Catalán, 2009).

Ediciones Universidad de Salamanca / @®@@ Stud. his., H. ${ }^{a}$ mod., 41, n. 2 (2019), pp. 303-338 
Las partidas destinadas al vestido y calzado, representan un porcentaje muy pequeño dado que las novicias aportaban su propio ajuar - hábito, ropa interior y ropa de cama-. La mayoría de los apuntes en este sentido se refieren a salarios en especie que perciben las criadas, el sacristán o el capellán.

En los presupuestos anuales no podían faltar los servicios de diferentes profesionales - cirujano, médico, criadas y lavandera - que percibían sus salarios de manera muy diferente. Hasta el siglo XVIII, los servicios externos requeridos se limitaban a la contratación de una o dos criadas, el cirujano y los gastos de botica. Las criadas cobraban un fijo monetario - pagado la mayoría de las veces cada tres años o más-, la manutención diaria, dos pares de zapatos al año, una cesta de manzanas, bulas y, de forma ocasional, ropa. Desde la década de 1680, el servicio de limpieza era complementado con la contratación de lavanderas externas para el lavado de los manteles. Esta práctica desapareció en 1750 cuando incrementen la nómina de criadas a 3 ó 4 personas. Con respecto a los servicios médicos, se pagaron a demanda hasta la segunda mitad del XVIII cuando regularizó en un fijo anual.

En el conjunto del presupuesto general, llama la atención el fuerte impacto que tuvo el mantenimiento del culto, especialmente, en épocas de coyuntura recesiva. Dentro de este concepto la partida más abultada correspondía al pago de los salarios del vicario, el sacristán y las músicas quienes percibían una cantidad monetaria además de una cántara de vino, un carnero y una carga de carbón por Navidad. Podría pensarse que, al tener su propio capellán, los gastos relativos a misas de funeral y aniversarios quedarían englobados como funciones propias del mismo. Nada más lejos de la realidad. Las monjas debieron sufragar sus entierros, misas de aniversario, y cada una de las funciones religiosas de acuerdo con la tarifa correspondiente. Si además requerían los servicios del cabildo parroquial había que añadir los emolumentos propios de uno de los participantes, lo que originaba un desembolso considerable.

El capítulo de explotación y gestión comprendía los gastos de administración (honorarios de peritos, escribanos, notarios, procuradores), de inversión (compra de animales, plantíos, examinar carbones, amojonamiento, etc.), de explotación (salarios, arreglo y mejora de las fincas y caserías, aperos de labranza, etc.) y financieros (deudas, censos, juros e impuestos). Hasta el siglo XVII, la mayor parte de este apartado lo conforman las gestiones derivadas del impago de los réditos de censos. A partir del siglo XVIII, el peso de esta partida se elevó hasta el 20-25 por 100 como resultado del proceso de amojonamiento y administración de las propiedades recién adquiridas. Con el inicio del ciclo bélico a finales del Setecientos, esta partida se elevó hasta casi al 30 por 100 del total debido al fuerte incremento de la presión fiscal que afectó al clero vizcaíno y sus propiedades.

Cada uno de estos apartados merecería un estudio pormenorizado. Sin embargo, este trabajo se va a centrar en el análisis de las compras de alimentos por ser el que tuvo más importancia en el conjunto del presupuesto. 


\section{ABASTO DE ALIMENTOS EN EL CONVENTO DE LA MERCED DE MARKINA}

Se ha escrito mucho sobre los condicionantes que determinan que un determinado grupo social consuma un tipo u otro de alimentos. Factores culturales, ecológicos, geográficos y económicos fueron modelando los hábitos alimenticios de la población ${ }^{21}$. De todos ellos, quizá el que tuvo mayor importancia fue la condición social del consumidor ya que ésta determinaba su poder adquisitivo y, por tanto, su capacidad de acceso a determinados bienes (Bernardos, 2004b: 5). Así, la literatura señala las mesas de conventos y monasterios entre las mejor surtidas de la Edad Moderna, tanto en cantidad como en variedad ${ }^{22}$.

No cabe duda de que las limitaciones alimentarias impuestas en las constituciones de cada orden religiosa jugaron un papel homogeneizador en las dietas conventuales, aunque en la mayoría de los casos se limitaban a establecer los días de ayuno y delimitar los que se podía comer carne - domingo, martes y jueves - o «pescado, huevos o grosura» (Constituciones, 1624). En general, la dieta de los conventos era similar a la de las clases populares en los alimentos básicos como pan, carne, vino, legumbres, frutas y verduras. Sin embargo, lo que las diferenciaba unas de otras era la cantidad y calidad de las especies elegidas: carne de cordero o cabrito frente a buey, pan blanco frente a pan moreno, trigo frente a centeno o maíz y el uso de algunos productos especiales como las confituras, especies, quesos, chocolate, etc. (Eirás, 1993:42).

El menú teórico que proponían muchas congregaciones se vio reducido por las disponibilidades económicas de cada convento, marcando diferencias entre ellos, aunque en todos los casos se presume que la ingesta calórica era más elevada que la del promedio de la población (Eirás, 1974:105-108). Por ejemplo, en los conventos de clarisas del País Vasco, las raciones de pan y vino eran bastante homogéneas, pero existen diferencias remarcables en lo que se refiere a la carne, pescado y productos especiales ya que su consumo estaba en función de la cuantía de la dote aportada (Piquero, 2000:231). En cualquier caso, sus despensas no tenían nada que ver con las de conventos andaluces, como el de Santa Ana de Córdoba que registra 109 referencias de alimentos diferentes (Gómez Navarro y Villegas, 2015:99) o las cantidades y variedad de especies consumidas en los grandes monasterios medievales ${ }^{23}$.

21. Entre otras cabe destacar Martínez Llopis, 1989; Montanari, 1993; Montanari y Flandrin, 1996; Kiple y Ornelas, 2000; Allen y Albalá, 2003; Sarti, 2003; Bernardos, 2004b; Gentilcore, 2015.

22. Gras, 1996; Piquero, 2000; Langue y Zabala, 2000; Burgo López, 1987; Gómez Navarro, 2010; Gómez Navarro y Villegas Becerril, 2015.

23. Por ejemplo, en Nuestra Señora de Guadalupe en 1543 se daban 1500 raciones diarias para las que se compraban entre diez o doce mil fanegas de trigo, veinte mil arrobas de vino o siete mil cabezas de ganado de todo tipo (Gómez Díaz, 2001:383).

Ediciones Universidad de Salamanca / @®@@ Stud. his., H. ${ }^{a}$ mod., 41, n. 2 (2019), pp. 303-338 
El patrón de consumo del convento de la Merced de Markina se corresponde con el apuntado para los conventos vascos por Piquero (2000: 230) e Intxaustegui (2018:238-250), aunque sufrió variaciones a lo largo del periodo analizado. En líneas generales se puede afirmar que, durante el siglo XVII, la dieta de las monjas fue bastante monótona con productos procedentes de los mercados locales -a excepción del trigo y el aceite - y con escasa presencia de aquellos cuyo consumo estaba asociado a las rentas más altas. A lo largo del siglo XVIII, fueron incrementando su dependencia del mercado al reducir los alimentos de producción propia e incorporando alguna delicatesen como el chocolate, el arroz, los frutos secos y especias utilizadas en repostería (Anexo I). La dieta real debió completarse con verduras, frutas y hortalizas procedentes de su propia huerta, que era cuidada con esmero a juzgar por el gasto anual que realizaban en estiércol, simientes, salarios en cavarla o el arreglo de tapias y sistemas de riego. Esta evolución queda reflejada en el la distribución porcentual que tuvieron los alimentos básicos en el conjunto del presupuesto (Gráfico 2).

\section{Gráfico 2}

Distribución porcentual del gasto en alimentación en el convento de la Merced de Markina, 1585-1824

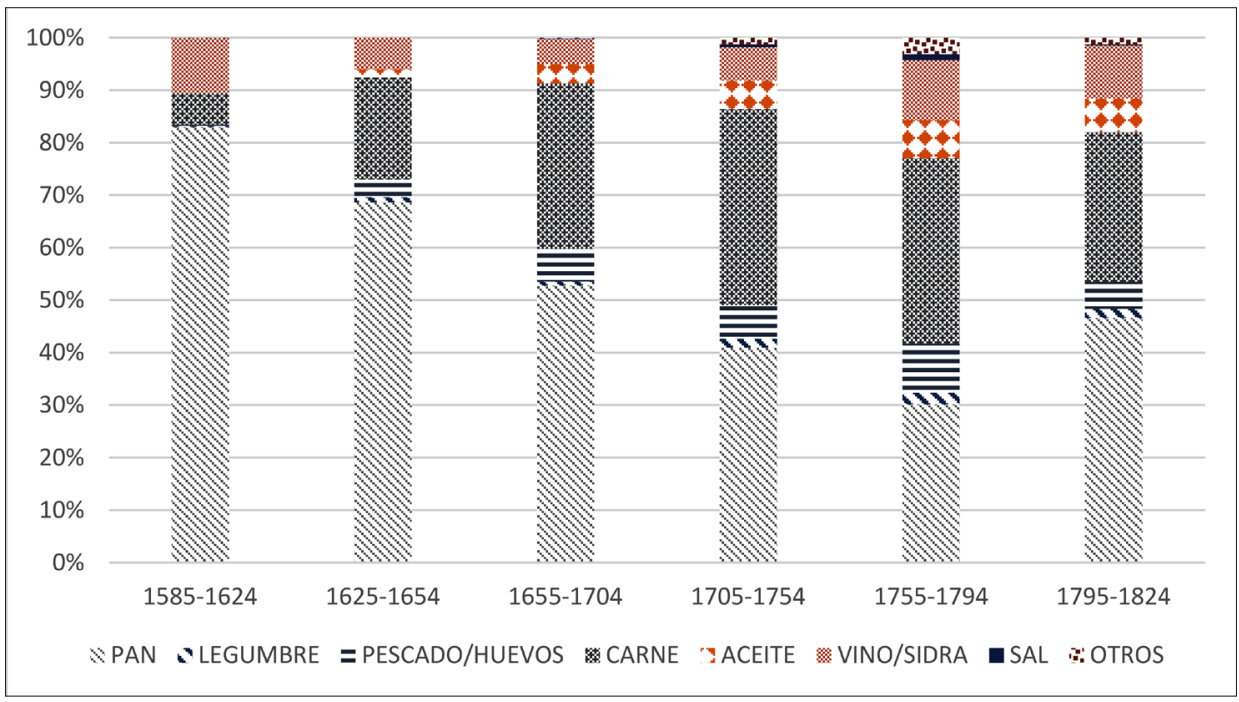

Elaboración propia. AMMB-AM- Libros de gastos y de recibos

En la etapa comprendida entre 1585-1624, el convento apenas recurrió al mercado para el abastecimiento de alimentos. La compra de trigo era la partida 
más importante ya que suponía el 85 por 100 del gasto, seguida de los costes de producción de la sidra, la adquisición de un buey y un cerdo para la matanza, y pequeñas cantidades de legumbre, pescado y aceite. Una vez que ingresan en clausura, los réditos de los censos permitieron ampliar el umbral de gasto $\mathrm{y}$, con ello, la cantidad y calidad de bienes adquiridos. A partir de aquí y hasta finales del siglo XVIII, la importancia relativa de la compra de cereal no dejó de reducirse frente al avance de los productos cárnicos, del pescado, del vino, del aceite o de las especias y coloniales.

\subsection{Cereales y Legumbres}

La compra de trigo fue sin duda la partida más importante del gasto diario, aunque como acabamos de ver fue reduciendo su importancia relativa a lo largo de los siglos XVII y XVIII. Este cereal no solo servía para elaborar pan, sino que se utilizó como moneda de pago de rentas, salarios, réditos de censos consignativos o devolución de préstamos. Es decir, se trataba de un producto que excedía lo puramente alimenticio y con enorme valor añadido en el Antiguo Régimen, puesto que, en muchos momentos, adquirió la categoría de bien de inversión debido a su facilidad de almacenamiento y demanda inelástica ${ }^{24}$.

La gestión del abasto del grano fue sufriendo variaciones a lo largo del periodo analizado acomodándose a la composición y cuantía de las rentas del convento e intentando siempre cubrir los mínimos vitales de las monjas. Si se considera el desembolso global en concepto de trigo y/o pan realizado por la institución, se puede comprobar que, hasta comienzos del siglo XVIII, el convento recurrió fundamentalmente al mercado, complementándolo con pequeñas compras de pan elaborado y algún aporte puntual procedente del pago de réditos de censos en esta especie. El cambio de modelo económico, en el que la actividad crediticia fue sustituida por la explotación de fincas rústicas, permitió la progresiva sustitución del grano comprado por el que obtenían de la renta de sus propiedades, al principio de forma parcial hasta acabar por sustituirlo completamente (Tabla 2).

24. «Recibiéronse 100 ducados de vellón del premio de 200 ducados de la plata de la dote de Ursula san Francisco que mandó el maestro provincial se comprase de trigo y estuviese siempre en trigo o en dinero» 1651. [AMMB- AM- 0011/001-00].

Ediciones Universidad de Salamanca / అ@@ Stud. his., H. ${ }^{a}$ mod., 41, n. 2 (2019), pp. 303-338 
ELENA CATALÁN MARTÍNEZ

LAS COSAS DEL COMER. EVOLUCIÓN DEL GASTO ALIMENTICIO

EN UN CONVENTO RURAL DE BIZKAIA, (1585-1825)

Tabla 2.

Gasto de pan y trigo en el convento de la Merced de Markina, 1585-1824

\begin{tabular}{|c|c|c|c|c|c|}
\hline & $\begin{array}{c}\text { Compras } \\
\text { Trigo } \\
\text { \% }\end{array}$ & $\begin{array}{c}\text { Renta } \\
\text { Trigo } \\
\text { \% }\end{array}$ & $\begin{array}{c}\text { Panes } \\
\text { Elaborados } \\
\text { \% }\end{array}$ & $\begin{array}{c}\text { Hornera } \\
\%\end{array}$ & $\begin{array}{c}\text { Promedio de } \\
\text { gasto anual por } \\
\text { monja (rsv.) }\end{array}$ \\
\hline $1585-1624$ & 92,4 & 7,6 & - & - & 103 \\
\hline $1625-1654$ & 92,2 & 7,8 & - & - & 108 \\
\hline $1655-1704$ & 88,1 & 5,8 & 5,8 & 0,4 & 164 \\
\hline $1705-1754$ & 74,3 & 21,2 & 2,9 & 1,6 & 133 \\
\hline $1755-1794$ & 42,4 & 43,6 & 12,2 & 1,8 & 259 \\
\hline $1795-1824$ & - & 84,6 & 8,7 & 6,7 & 71 \\
\hline
\end{tabular}

Elaboración propia. AMMB-AM- Libros de gastos y de recibos.

Hasta 1590, el trigo se obtenía en exclusiva de la dotación fundacional que incluía 50 fanegas anuales. Esta renta permitía la manutención de 8 monjas, considerando que, según estipulaban las autoridades de la orden, el consumo establecido para cada una era de 0,5 fanegas mensuales -721 gramos diarios de trigo en grano por monja $-{ }^{25}$. Sin embargo, la decisión del patrón de dejar de pagar la renta por incumplimiento de las condiciones de la fundación obligó a las monjas a adquirir trigo en el mercado - entre 6 y 8 fanegas al mes - para cubrir las necesidades diarias, más un pequeño remanente para el pago de salarios y otras necesidades de la casa. Según los apuntes en el libro de gastos, este trigo procedía fundamentalmente de Castilla y solo se recurría al trigo «de la mar» o al local en momentos de escasez o dificultades en el transporte.

A partir de la ruptura con la casa de Bidarte y su constitución como convento de clausura, las necesidades de trigo no dejaron de crecer habida cuenta de que se produjo un fuerte incremento de las vocaciones y, por lo tanto, de bocas que alimentar. Entre 1624 y 1670, la ración mínima de pan por persona estuvo garantizada gracias a los ingresos de una fuerte actividad crediticia desplegada por el convento en la segunda mitad de la centuria. El abastecimiento continuó haciéndose en el mercado, con la única salvedad de que aceptaron el pago de algunos réditos en especie - trigo, animales, carbón o hierro - ante la dificultad de los censatarios de efectuar su pago en metálico. Es más que probable que la molienda del grano formara parte de las

25. Eirás (1993:40-43) apunta un consumo medio de entre 430-460 gramos de pan por persona y día en las ciudades españolas de la segunda mitad del siglo XVI y de unos 900 gramos para las clases privilegiadas en el mismo periodo.

Ediciones Universidad de Salamanca / @®@@ Stud. his., H. ${ }^{a}$ mod., 41, n. 2 (2019), pp. 303-338 
obligaciones de los propietarios de molinos deudores del convento, ya que en la contabilidad no aparece ningún apunte relativo a este proceso.

A partir de 1674, comenzaron a anotarse en las partidas de gasto el coste de las «coceduras», de lo que podemos inferir que hasta ese momento las monjas elaborarían el pan en el propio convento. Además de la externalización de la parte final de la producción, se decidió adquirir pan ya elaborado para suplir los déficits originados en la compra mensual de trigo. Durante un brevísimo periodo de tiempo (1676-1689), se consignaron los días de cada mes en los que tuvieron que recurrir a este complemento, el número de monjas para el que se realizaba la compra, el precio de la libra de $\operatorname{pan}^{26}$ y el importe total desembolsado por este concepto. Estos datos permiten calcular el tamaño de la ración diaria por monja, así como el peso que tuvieron estas compras sobre el conjunto del gasto en el abastecimiento de pan (Tabla 3). Las cantidades ingeridas por las monjas de Markina responden a los estándares de consumo señalados por la historiografía española y europea, aunque se pueden calificar como austeras si lo comparamos con el consumo estimado para otras instituciones rentistas ${ }^{27}$.

Tabla 3.

«Faltas de pan» en el convento de la Merced de Markina, 1676-1689

(Promedios anuales)

\begin{tabular}{|c|c|c|c|}
\hline & $\begin{array}{c}\text { Promedio de días } \\
\text { con «faltas» al mes }\end{array}$ & $\begin{array}{c}\text { Libras de pan } \\
\text { comprado por día y } \\
\text { monja }\end{array}$ & $\begin{array}{c}\text { \% de pan comprado } \\
\text { sobre el total de gasto } \\
\text { en trigo/pan }\end{array}$ \\
\hline $1676-1679$ & 6,5 & 0,618 & 10,0 \\
\hline $1680-1684$ & 9,3 & 0,508 & 13,0 \\
\hline $1685-1689$ & 7,9 & 0,635 & 11,7 \\
\hline $1676-1689$ & 7,9 & 0,587 & 13,4 \\
\hline
\end{tabular}

Elaboración propia. AMMB-AM Libros de gastos y de recibos.

A partir de 1720, el grano comprado se complementó con partidas de trigo procedentes del pago de la renta de tierras y caserías adquiridas en las décadas anteriores. Al parecer, el convento decidió exigir parte del pago de la renta de la

26. La referencia del precio, dentro del mismo año, la hacen indistintamente a la libra de pan o a la unidad por lo que se ha dado por sentado que cada pan pesaba una libra.

27. Livi-Bacci, 1988: 142-145; Montanari, 1993:106-107; Allen, 2001: 421; Bernardos, 2004b: 14; González- Mariscal, 2015:18; Calderón, García-Montero y Llopis, 2017: 25-26; López y Piquero, 2016:14; Eirás, 1993: 40-43.

Ediciones Universidad de Salamanca / @®@@ Stud. his., H. ${ }^{a}$ mod., 41, n. 2 (2019), pp. 303-338 
tierra en trigo para poder utilizarlo en el consumo cotidiano de la casa y reducir así la partida de gasto alimenticio en un momento en el que la demanda se disparaba por el incremento de los costes salariales pagados en especie. En consecuencia, la cantidad de cereal procedente del mercado fue reduciendo su importancia relativa hasta desaparecer por completo en 1780, cuando se decidió cobrar todos los arrendamientos en trigo y minimizar así el fuerte incremento de los precios de este cereal. Durante todo este periodo se consolidó la práctica de completar los posibles déficits con la compra de pan ya horneado, llegando a cubrir con este sistema en torno al 12 por 100 de las necesidades anuales.

Como se puede deducir, con los datos que aportan los libros de cuentas resulta imposible calcular las raciones diarias de pan que se consumían en el convento. En primer lugar, los datos hacen referencia a las compras globales de cereal, lo que no es sinónimo de consumo per cápita. Segundo, desconocemos qué cantidad de lo comprado se destinaba al pago de salarios, agasajos para visitas y limosna para pobres. Tercero, no conocemos ni la variedad o calidad del trigo utilizado, ni su tasa de rendimiento en molturación, ni la proporción de harina empleada por cada libra de $\operatorname{pan}^{28}$. Y, por último, tampoco se sabe el peso ni calidad de los panes que se compran ya elaborados para completar el consumo mensual. En cualquier caso, fuera cual fuese la ración ingerida por cada monja, el auténtico privilegio en el mundo rural atlántico lo constituía el hecho de consumir pan de trigo en lugar de «talo» o pan de maíz, dominante en la dieta campesina de la cornisa cantábrica (Fernández de Pinedo, 1974:120; Piquero, 2000: 229-231).

Con respecto al consumo de otros cereales, este es insignificante. Como en otros conventos de la zona, el maíz estuvo destinado a alimentar a los cerdos cuya crianza permitía abastecer la despensa de productos de matanza (Langue y Zabala, 2000: 26). También se registran compras ocasionales de cebada que debieron servir para alimentar a las caballerías, ya que no hay indicio de elaboración de cerveza. Por último, a partir de 1753, se introduce el arroz en la dieta a través de un postre asociado al tiempo de vigilia, el arroz con leche.

Las legumbres que constituían uno de los pilares de la alimentación en la época preindustrial, al menos entre las clases populares, no tuvieron una importancia destacada en la cesta de la compra del convento. Como se puede ver en la Tabla 4 , en la que se ofrece a modo de proxi de consumo la cantidad de legumbres que se adquirieron por monja y día, la ingesta diaria estaría por debajo de la ración

28. Allen (2001:419) establece una tasa de rendimiento del grano en molturación del 83 por 100 y una proporción de harina de 3 libras y 2 onzas por cada 4 libras de pan. López y Piquero (2016: 14) estiman una proporción de harina por pan muy similar para el «pan de ciudad» mientras que el pan común tendría un 30 por 100 de pérdida durante su elaboración (Andrés y Lanza, 2012:66; Piquero, 2000:230).

Ediciones Universidad de Salamanca / అ@@ Stud. his., H. ${ }^{a}$ mod., 41, n. 2 (2019), pp. 303-338 
estándar de legumbre cocida por persona, que suele estar en torno a los 170 gramos por person ${ }^{29}$. Fundamentalmente consumieron habas, alubias y guisantes mientras que los garbanzos quedarían reservados para la Cuaresma por su mayor precio ${ }^{30}$.

Tabla 4.

Distribución porcentual de legumbres adquiridas en el convento de la Merced de Markina, 1585-1824 (\% sobre su peso en fanegas)

\begin{tabular}{|c|c|c|c|c|c|c|c|}
\hline & $\begin{array}{c}\text { Alubias } \\
\%\end{array}$ & $\begin{array}{c}\text { Habas } \\
\%\end{array}$ & $\begin{array}{c}\text { Gar- } \\
\text { banzos } \\
\%\end{array}$ & $\begin{array}{c}\text { Gui- } \\
\text { santes } \\
\%\end{array}$ & $\begin{array}{c}\text { Sin } \\
\text { especi- } \\
\text { ficar } \\
\%\end{array}$ & $\begin{array}{c}\text { Gramos de } \\
\text { legumbre } \\
\text { en seco } \\
\text { por monja } \\
\text { y día\% }\end{array}$ & $\begin{array}{c}\text { Promedio } \\
\text { gasto } \\
\text { anual por } \\
\text { monja } \\
\text { (rsv) }\end{array}$ \\
\hline $\mathbf{1 5 8 5 - 1 6 2 4}$ & - & 87,1 & 12,9 & - & - & 28 & 0,1 \\
\hline $\mathbf{1 6 2 5 - 1 6 5 4}$ & 12,9 & 48,5 & 19,3 & 19,3 & - & 20 & 0,6 \\
\hline $\mathbf{1 6 5 5 - 1 7 0 4}$ & 11,7 & 19,8 & 24,8 & 16,6 & 27,1 & 34 & 0,9 \\
\hline $\mathbf{1 7 0 5 - 1 7 5 4}$ & 11,9 & 15,9 & 16,9 & 8,0 & 47,4 & 33 & 3,2 \\
\hline $\mathbf{1 7 5 5 - 1 7 9 4}$ & 12,5 & 39,8 & 18,2 & - & 29,5 & 43 & 6,5 \\
\hline $\mathbf{1 7 9 5 - 1 8 2 4}$ & 39,0 & - & 11,8 & - & 49,2 & 10 & 2,1 \\
\hline
\end{tabular}

Elaboración propia. AMMB-AM Libros de gastos y de recibos.

* Se ha establecido la equivalencia de 1 fanega de legumbre en 56, 92 kilos (Carrión, 1996:65).

\subsection{La carne}

El consumo de carne estaba muy condicionado por el calendario litúrgico que la prohibía en periodos concretos del año - Cuaresma y entre la Pascua de Resurrección y la de Pentecostés - y prácticamente la hacía obligatoria en determinadas festividades ${ }^{31}$. Las enfermas estaban dispensadas de su cumplimiento y tenían permiso para consumir carnero, que era la variedad más apreciada por nobles, eclesiásticos y

29. Hay que tener en cuenta que se trata de peso en seco y que, por tanto, hay que multiplicar estas cantidades por tres ya que las legumbres suelen triplicar su peso cuando se consumen cocidas.

30. En el dezmatorio de la villa, las legumbres aparecieron de forma tardía ya que no se contabilizan hasta mediados del siglo XVIII y, cuando lo hacen, se trataba de alubias y habas [Archivo Catedral de Calahorra [ACC]. Averiguaciones de veros valores. 1545, Libro 271; 1588-1592, carpeta 2243; y 1771-1771 legajo 3899].

31. En 1767, el convento de la Santísima Trinidad de Bidaurreta en Oñate (Gipuzkoa) señala en 209 días los que las monjas «tienen libertad de comer carne» (Piquero 2000: 230).

Ediciones Universidad de Salamanca / @@@ Stud. his., H. ${ }^{a}$ mod., 41, n. 2 (2019), pp. 303-338 
familias con alto poder adquisitivo (Bernardos, 2004a:280). Así mismo, este animal constituía un «aguinaldo», junto con el vino y el carbón, para el vicario y las monjas encargadas de tocar el piano y el arpa.

Como en el resto de la España atlántica, el convento de Markina mostró una clara preferencia por la carne de vacuno y porcino, reservando el ovino para las dietas especiales o para las celebraciones religiosas. Hasta la década de 1660 predominó la carne de cerdo, criado y embutido en casa, sobre el vacuno que también se consumía preferentemente curado. A partir de ese momento, la contabilidad registra compras sistemáticas de tocino y manteca, destinadas a completar el producto propio, así como un incremento en el consumo regular de carne fresca de vaca, tendencia que se acabaría consolidando a lo largo del siglo XVIII ${ }^{32}$ (Tabla 5). Por último, apenas se registran partidas de volatería: algún que otro capón con motivo de la visita de los provinciales de la orden y gallinas de forma esporádica, tanto para la producción de huevos como para consumo de las enfermas.

Tabla 5.

Distribución porcentual del gasto de carne en el convento de la Merced de Markina, $1585-1824$

\begin{tabular}{|c|c|c|c|c|c|c|c|c|}
\hline Periodo & Porcino & Manteca & Tocino & $\begin{array}{c}\text { Cerdo } \\
\text { vivo }\end{array}$ & Vacuno & Cecina & Vaca & Carnero \\
\hline & $\begin{array}{c}\text { \% total } \\
\text { carne }\end{array}$ & \multicolumn{3}{|c|}{$\begin{array}{c}\text { \% sobre total } \\
\text { de porcino }\end{array}$} & $\begin{array}{c}\text { \% total } \\
\text { carne }\end{array}$ & $\begin{array}{c}\text { \% sobre total de } \\
\text { vacuno }\end{array}$ & $\begin{array}{c}\text { \% total } \\
\text { carne }\end{array}$ \\
\hline $\mathbf{1 5 8 5 - 1 6 2 4}$ & $\mathbf{5 8 , 1}$ & - & - & 100 & $\mathbf{3 5 , 0}$ & 65,8 & 34,2 & $\mathbf{6 , 9}$ \\
\hline $\mathbf{1 6 2 5 - 1 6 5 4}$ & $\mathbf{5 6 , 5}$ & - & 6,3 & 93,7 & $\mathbf{4 1 , 6}$ & 88,1 & 11,9 & 1,9 \\
\hline $\mathbf{1 6 5 5 - 1 7 0 4}$ & $\mathbf{3 1 , 8}$ & 1,2 & 35,9 & $\mathbf{6 2 , 9}$ & $\mathbf{6 2 , 9}$ & 21,1 & 78,9 & $\mathbf{5 , 3}$ \\
\hline $\mathbf{1 7 0 5 - 1 7 5 4}$ & $\mathbf{4 4 , 2}$ & 0,2 & 22,4 & 77,4 & $\mathbf{5 0 , 5}$ & 9,2 & 90,9 & $\mathbf{5 , 3}$ \\
\hline $\mathbf{1 7 5 5 - 1 7 9 4}$ & $\mathbf{4 4 , 7}$ & 2,2 & 63,6 & 34,3 & $\mathbf{5 5 , 3}$ & 6,0 & \multicolumn{2}{|c|}{$94,1 *$} \\
\hline $\mathbf{1 7 9 5 - 1 8 2 4}$ & $\mathbf{2 3 , 8}$ & 0,6 & 23,0 & 76,3 & $\mathbf{7 6 , 2}$ & 6,0 & \multicolumn{2}{|c|}{$94,0 *$} \\
\hline
\end{tabular}

Elaboración propia. AMMB-AM Libros de gastos y de recibos.

* La vaca y el carnero aparecen agregados en la misma partida por lo que no se puede discriminar.

La evolución del gasto medio por monja realizado por el convento revela diferentes coyunturas en la demanda de carne (Gráfico 3).

32. Fernández de Pinedo (2015:302) constata un incremento de la carne de vacuno en Bilbao entre 1640-1690, lo que acabaría repercutiendo en una reducción en su precio.

Ediciones Universidad de Salamanca / అ@@ Stud. his., H. ${ }^{a}$ mod., 41, n. 2 (2019), pp. 303-338 
Gráfico 3.

Promedio de gasto anual en carne por monja en reales plata

Convento de la Merced de Markina, 1584-1825

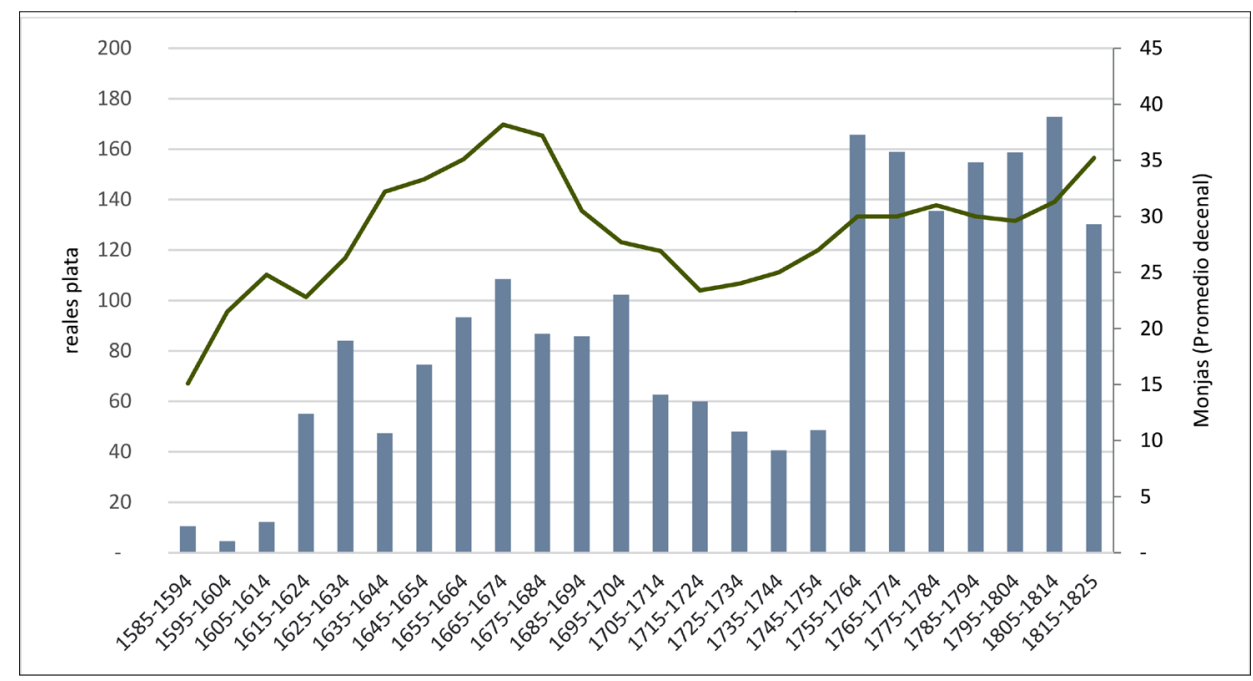

Elaboración propia. AMMB-AM Libros de gastos y de recibos.

Durante la etapa de beaterio, su escasa capacidad de compra determinó un consumo esporádico de carne limitado a la compra de buey y cerdo para la matanza, cecina destinada a las novicias y la organista, y carnero para enfermas. Una vez que se constituyeron como convento de clausura, se priorizó la compra de lechones sobre la de cerdos ya criados. Los «gruñentes» se compraban en los meses de enero-febrero, se alimentaban con castañas, bellotas o maíz y se sacrificaban a final de año por san Martín. Este momento coincidía con la adquisición de un buey para matarlo, hacer cecina y beneficiarse del cuero. En todos los casos, el consumo de carne era en forma de embutido o salazón; solo cuando recibían la visita de sus superiores, o con motivo de alguna festividad como la Asunción, comían carne fresca de vaca. A partir de la década de 1660, se generalizó su consumo diario, con el consiguiente incremento del gasto medio por monja. Este comportamiento difiere del que tuvieron otras instituciones eclesiásticas en las que apenas se consumía vaca por ser un producto de menor precio y considerarse un propio de clases sociales más bajas ${ }^{33}$. Sin duda,

33. Son muchos los trabajos sobre conventos que señalan la preferencia del carnero sobre la vaca, como alimento de mayor calidad y prestigio (Eirás, 1993; Piquero, 2000; Gómez Navarro, 2010; Gómez Navarro y Villegas, 2015). Bernardos (2004b) señala que en el Madrid

Ediciones Universidad de Salamanca / @®@@ Stud. his., H. ${ }^{a}$ mod., 41, n. 2 (2019), pp. 303-338 
en ello tuvo que influir la accesibilidad al mercado de vacuno, de producción local, y su menor precio ${ }^{34}$. Durante la primera mitad del siglo XVIII, el convento volvió a reducir su promedio de gasto por monja debido a una menor disponibilidad de numerario. El desembolso efectuado en la compra y acondicionamiento de propiedades inmuebles obligó a primar los productos procedentes de animales de crianza propia sobre los adquiridos en el mercado ya elaborados. Es a partir de la década de 1750 cuando el gasto cárnico se dispara, tanto por el alza de los precios como por el incremento de las cantidades consumidas. Durante este periodo, se observa un progresivo desplazamiento de la demanda hacia la carne de vacuno, quedando la de cerdo limitada a lo obtenido de la crianza de 3 o 4 lechones y la compra de tocino en el mercado local.

En general, a finales del siglo XVIII, el estamento eclesiástico había incrementado su consumo de carne alcanzando en torno a 229 gramos por persona y día, lo que superaba en unas 8,5 veces la media del país (Cubillo de la Puente, 1998: 282-283). Por encima de esta media se encontraban los representantes masculinos del clero en la cornisa cantábrica: 293 gramos, los canónigos de Cenarruza (Fernández de Pinedo, 1974:119-120) o los 334 gramos de los canónigos de la catedral de Santander (Lanza, 1991: 295). Los informes de la Real Sociedad Bascongada de Amigos del País (1768: 74 y 349-352) corroboran este incremento en el consumo de carne de la segunda mitad del siglo XVIII, dando noticia de la creación de carnicerías en pueblos que antes no tenían ${ }^{35}$. También se hacen eco de una curiosa invención que consistía en una especie de cámara de vacío que conservaba durante mucho tiempo los alimentos «sin exponerse al riesgo de que se corrompa» y permitía que los habitantes de las localidades más pequeñas pudiesen abastecerse de carne a «muchas leguas de distancia...». Sin embargo, esta expansión del consumo cárnico no debe llevarnos a engaño: a comienzos del siglo XIX, la carne era un producto urbano vinculado a niveles de renta medios y altos mientras que las proteínas finas de origen animal brillaban por su ausencia en las dietas campesinas (Fernández de Pinedo, 1974:120-121).

La contabilidad del convento no permite ir más allá en las apreciaciones de consumo de carne. En primer lugar, es difícil establecer el peso que lograban los lechones criados en casa en el momento de la matanza. Podríamos equipararlos

de principios del Seiscientos los trabajadores de las tahonas consumían carnero, mientras que, un siglo después, este había sido sustituido por carne de vacuno que era más barata.

34. Fernández de Pinedo (2015:302) señala que la mayor frecuencia del consumo de vaca repercutía en un precio más elevado para el carnero. El diferencial de precios entre ambos productos para Bilbao se estima en 1,98 por 100 y 1,95 por 100 en las décadas de 1640 y 1690 respectivamente, mientras que en Markina, este diferencial fue de 1,42 por 100 en 1615-1624 y de 1,56 por 100 entre $1685-1694$.

35. También se señala este incremento para Madrid Palacio Atard (1998:31-32).

Ediciones Universidad de Salamanca / @®@@ Stud. his., H. ${ }^{a}$ mod., 41, n. 2 (2019), pp. 303-338 
al peso que alcanzaban los cerdos comprados vivos para su sacrificio y que se situaba en unos 50 y 60 kilos por animal ${ }^{36}$. Pero, aun así, habría que descontar el peso perdido durante el proceso de curación, no así de la sangre y vísceras que se consumían embutidos. En segundo lugar, no hay evidencias de despiece de ganado vacuno, tal y como se hace hoy día. Es probable que el aprovechamiento de la pieza fuese mayor que el actual, por lo sería razonable aplicar una ratio del 86 por 100 sobre su peso en vivo (González-Mariscal, 2015, 16). Este cálculo nos serviría para determinar la cantidad de carne fresca obtenida, pero no en el caso de la elaboración de cecina. Tampoco sabemos que cantidad de ésta se compraba como complemento, excepto en el breve periodo comprendido entre finales del siglo XVII y primeras décadas del XVIII ${ }^{37}$. En tercer lugar, hasta 1756, la carne fresca se contabiliza por su peso e importe monetario. A partir de aquí, se cuantifica el gasto conjunto en vaca y carnero, sin discriminar ni peso ni especie como se venía haciendo hasta entonces.

\subsection{El pescado y huevos}

El contrapunto necesario al precepto de abstinencia de comer carne era el consumo de pescado y, en su defecto, huevos. Su ingesta estuvo ligada tanto a las festividades religiosas como a las obligaciones de ayuno y penitencia repartidas a lo largo del año ${ }^{38}$. En este sentido, se puede afirmar que la normativa religiosa contribuyó a adoptar unos hábitos alimenticios cardiosaludables al reducir la ingesta de grasa animal y propiciar el consumo regular de pescado a lo largo de todo el año. Este se degustaba preferentemente en salazón, incluso en aquellas localidades más próximas a la costa, ya que este sistema facilitaba no solo la conservación sino también su transporte, contribuyendo a su popularización ${ }^{39}$.

36. Peso según promedio de los cerdos comprados por el convento, de los que sí se especifica. La FAO (2017) establece en la actualidad un peso medio de $50 \mathrm{~kg}$ por animal, aunque varía según la raza y las condiciones medioambientales.

37. El consumo medio de cecina por monja entre finales del siglo XVII y primeras décadas del XVIII se sitúa entre 8,5 y 9 kilos anuales.

38. Según las Constituciones de la Orden de la Merced (1624:14) eran días de ayuno «los de las ledanías, los viernes, y vigilia de la Natibidad, Purificación, y Anunciación de nuestra Señora, la vigilia de Pentecostes, los días de las quatro témporas del año, y los demás ayunos de la Iglesia. Desde la feria segunda después de la dominica de la fiesta de Todos los Sanctos, hasta el día del Nacimiento de Christo. Y desde la dominica de la quinquagesima, hasta Pascua de Resurecion, ayunaremos continuamente todos los días...»

39. «Nuestro consumo de este género [bacalao] en vez de minorarse, vá subiendo furiosamente con la carestía de las carnes, tanto, que ya la pobre gente del campo le ha introducido aun en días de carne, así por falta de dichas carnes, como por la facilidad de su condimento...» Arriquibar 1779 [Recreación politica. Reflexiones sobre el amigo de los hombres en su tratado de población, considerando con respecto á nuestros intereses]. Cit. por Cubillo de la Puente,1998: 283.

Ediciones Universidad de Salamanca / @®@@ Stud. his., H. ${ }^{a}$ mod., 41, n. 2 (2019), pp. 303-338 
En el convento de Markina, a pesar de distar unos pocos kilómetros de puertos pesqueros $-11 \mathrm{~km}$ del puerto de Ondárroa y a $14 \mathrm{~km}$ del de Lekeitio-, se consumió preferentemente pescado en salazón (Tabla 6). El bacalao fue sin duda la especie preferida al estar señalado por las Constituciones de la mayoría de las órdenes religiosas como comida de referencia en tiempo de Cuaresma, complementado ocasionalmente con arenque y cecial.

Tabla 6.

Distribución porcentual del gasto de pescado y huevos en el convento de la Merced de Markina, 1585-1824

\begin{tabular}{|c|c|c|c|c|c|}
\hline & $\begin{array}{c}\text { Salazón } \\
(\%)\end{array}$ & $\begin{array}{c}\text { Fresco } \\
(\%)\end{array}$ & $\begin{array}{c}\text { Fresco y huevos } \\
(\%)\end{array}$ & $\begin{array}{c}\text { Portes } \\
(\%)\end{array}$ & $\begin{array}{c}\text { Promedio } \\
\text { gasto anual } \\
\text { por monja } \\
(\mathbf{\% s v})\end{array}$ \\
\hline $\mathbf{1 5 8 5 - 1 6 2 4}$ & 100 & - & - & - & 4,0 \\
\hline $\mathbf{1 6 2 5 - 1 6 5 4}$ & 98,9 & 1,1 & - & - & 16,3 \\
\hline $\mathbf{1 6 5 5 - 1 7 0 4}$ & 89,8 & 9,0 & 0,2 & 1,0 & 22,4 \\
\hline $\mathbf{1 7 0 5 - 1 7 5 4}$ & 54,8 & 36,9 & 6,9 & 1,4 & 17,5 \\
\hline $\mathbf{1 7 5 5}-1794$ & 43,8 & 10,7 & 45,2 & 0,4 & 45,9 \\
\hline $\mathbf{1 7 9 5 - 1 8 2 4}$ & 47,1 & 7,3 & 43,7 & 1,8 & 24,1 \\
\hline
\end{tabular}

Elaboración propia. AMMB-AM Libros de gastos y de recibos.

El pescado fresco se reservaba únicamente para las que estaban enfermas, siendo tan estrecha la percepción de este producto como una comida «saludable» que, hasta la década de 1630 , se contabilizaba junto al aceite y la legumbre en una partida que denominaban «gasto ordinario» y para la que calculaban 2,5 reales diarios por monja ${ }^{40}$. Durante el último tercio del siglo XVII, se inició un gradual cambio en las pautas de consumo al ampliarse el espectro de especies en fresco: congrio, atún, chipirones, besugo y, sobre todo, merluza. En conjunto, el pescado fresco fue ganando peso relativo -7 por 100 del total del gasto alimenticio-favorecido, sin duda por mejora de la red viaria que permitió un precio más asequible.

Simultáneamente, se generalizó la compra de huevos. La primera se registró en los libros de cuentas en 1691, lo que no implica que no hubiera consumo en fechas

40. Existía toda una cultura de alimentos adecuados en caso de enfermedad entre los que destacaban los caldos de aves y pescados blancos. Las carnes rojas, alimentos grasos o ácidos estaban totalmente contraindicados (Albalá, 2012:324).

Ediciones Universidad de Salamanca / అ@@ Stud. his., H. ${ }^{a}$ mod., 41, n. 2 (2019), pp. 303-338 
más tempranas puesto que hay constancia de crianza de gallinas en el convento ${ }^{41}$. Lo más probable es que a partir de ese momento la demanda superarse con mucho a capacidad de puesta de las aves, teniendo que recurrir al mercado para abastecerse. Al principio este producto estaba reservado exclusivamente para la cena de los domingos, aunque poco a poco se fueron incorporando a los menús de los viernes de vigilia y a los de las témporas -12 días al año, 3 por cada témpora-. Huevos y pescado fresco se consolidaron como alimentos habituales a partir del siglo XVIII, como signo de distinción social ya que ambos formaban parte de los alimentos «con prestigio» (Montanari, 1993:85).

\subsection{Sidra y Vino}

La ingesta de alcohol durante el Antiguo Régimen alcanzaba unos niveles muy elevados ya que proporcionaba un complemento calórico de fácil e inmediata utilización y se consideraba que tenía propiedades terapéuticas, especialmente en el caso del vino (Montanari, 1993:121-123). En la cornisa cantábrica, la sidra jugó este papel durante los siglos XVI y XVII. Sin embargo, a medida que el cultivo del maíz sustituía a las pomaradas, su consumo se vio relegado a un segundo plano para ser sustituido por el vino durante el siglo XVIII (Tabla 7).

\section{Tabla 7.}

Gasto en bebidas alcohólicas en el convento de la Merced de Markina, 1585-1824

\begin{tabular}{|c|c|c|c|}
\hline AÑOS & $\begin{array}{c}\text { Promedio de gasto anual } \\
\text { por monja } \\
\text { (en reales de vellón) }\end{array}$ & $\begin{array}{c}\text { Sidra } \\
\%\end{array}$ & $\begin{array}{c}\text { Vino } \\
\%\end{array}$ \\
\hline $\mathbf{1 5 8 5 - 1 6 2 4}$ & 9,6 & 97,0 & 3,0 \\
\hline $\mathbf{1 6 2 5 - 1 6 5 4}$ & 7,2 & 99,6 & 0,4 \\
\hline $\mathbf{1 6 5 5 - 1 7 0 4}$ & 13,2 & 100 & - \\
\hline $\mathbf{1 7 0 5 - 1 7 5 4}$ & 21,6 & 49,0 & 51,0 \\
\hline $\mathbf{1 7 5 5 - 1 7 9 4}$ & 58,8 & 1,8 & 98,2 \\
\hline $\mathbf{1 7 9 5 - 1 8 2 4}$ & 46,8 & - & 100 \\
\hline
\end{tabular}

Elaboración propia. AMMB-AM Libros de gastos y de recibos.

Hasta 1740, las mercedarias consumieron casi exclusivamente sidra, reservando pequeñas cantidades de vino para ocasiones especiales como la toma de velo negro

41. En 1681, se registra la compra de 18 gallinas a 3 reales cada una, destinadas al alimento de 9 monjas que comían carne en Cuaresma «dos gallinas por cada una por estar enfermas».

Ediciones Universidad de Salamanca / అ@@ Stud. his., H. ${ }^{a}$ mod., 41, n. 2 (2019), pp. 303-338 
(clausura) cuando se trasladaron de convento. La sidra era elaborada en su propio lagar, por lo que el gasto computado por este concepto corresponde a los costes de producción: salarios de trabajo de las pomaradas (cavar y nuevos plantones); equipamiento y mantenimiento del lagar (cubas, sebo y arreglos) o su alquiler; compra de manzanas adicionales, de las que explicitan su cuantía y precio; y, por último, el coste de majar el fruto y encubarlo. Solo ocasionalmente se compraba sidra elaborada si la producción propia no llegaba para cubrir las necesidades de la comunidad (Tabla 8).

Tabla 8 .

Composición porcentual de los costes de producción de elaboración de la sidra en el convento de la Merced de Markina, 1584-1733

\begin{tabular}{|c|c|c|c|c|c|c|}
\hline & $\begin{array}{c}\text { Extra } \\
\text { Sidra } \\
\%\end{array}$ & $\begin{array}{c}\text { Extra } \\
\text { Manzanas } \\
\%\end{array}$ & $\begin{array}{c}\text { Elaboración } \\
\%\end{array}$ & $\begin{array}{c}\text { Lagar } \\
\%\end{array}$ & $\begin{array}{c}\text { Precio } \\
\text { por cesta } \\
\text { manzana } \\
(\text { rsv })\end{array}$ & $\begin{array}{l}\text { Índice del } \\
\text { coste de } \\
\text { elaboración } \\
\text { de la sidra }\end{array}$ \\
\hline $1585-1624$ & 13,2 & 55,0 & 16,1 & 15,7 & 2,2 & 100 \\
\hline $1625-1654$ & 4,0 & 68,0 & 20,4 & 13,3 & 3,1 & 106 \\
\hline $1655-1693$ & 10,8 & 59,2 & 28,8 & 5,1 & 3,8 & 183 \\
\hline $1694-1733$ & 0,9 & 46,5 & 53,3 & - & 4,9 & 173 \\
\hline
\end{tabular}

Elaboración propia. AMMB-AM Libros de gastos y de recibos.

Mientras dependieron de la casa de Bidarte, la producción del pequeño manzanal de su propiedad se realizaba en el lagar del patrón, previo pago de un alquiler. Al trasladarse de ubicación, construyeron uno propio y lo dotaron de una cuba. Sin embargo, pronto resultó insuficiente para cubrir la demanda de una comunidad en plena expansión, por lo que en 1637 se compraron dos cubas nuevas. El incremento de la capacidad de producción obligaba a recurrir a la compra sistemática de manzanas - lo que suponía la mitad de los costes - que cada vez estaban más caras por la reducción de pomaradas como consecuencia de la expansión de los cultivos de maíz. También se tenía que recurrir a la adquisición de sidra ya elaborada puesto que la de producción propia no cubría las necesidades anuales.

Entre 1732 y 1740 los libros de cuentas no registran ninguna partida referente a la producción o compra de sidra, pero tampoco de ninguna otra bebida alcohólica. La documentación no aporta ningún dato del porqué de este comportamiento y es poco probable que se deba a una laguna documental ya que el resto de productos si aparecen correctamente contabilizados. Sea como fuere, en 1740 aparece por primera vez la compra a gran escala de vino clarete navarro y de pequeñas cantidades de vino dulce de Málaga, mientras que la sidra queda reservada exclusivamente para 
el pago del salario de las criadas y del capellán. Se podría pensar que esta decisión pudo estar motivada por el encarecimiento de la elaboración de la sidra, pero esto no parece ser determinante habida cuenta de que el gasto anual por persona en alcohol se duplicó con la compra de vino (Tabla 7). Probablemente fue una disposición de orden superior, aunque no tenemos constancia de ello. Sea como fuere, la elaboración de sidra quedó como un mero vestigio del pasado.

\subsection{Aceite de oliva}

El aceite de oliva es uno de esos productos con múltiples aplicaciones en la economía de Antiguo Régimen: alimentación, iluminación y elaboración de jabón (Hernández García, 2007:79). En el mundo rural la grasa animal, más accesible y asequible que el aceite, era de uso común, aunque debía sustituirse por aceite los días de abstinencia.

Hasta 1630, el convento computó el aceite en un agregado monetario junto al pescado ya que como se ha visto estaba destinado al ayuno y al consumo de las enfermas. A partir de esa fecha y hasta 1644, las anotaciones pasaron a ser mensuales señalando la cantidad, precio y utilidad del aceite comprado lo que nos permite calcular el porcentaje destinado a uno u otro uso (Tabla 9).

Tabla 9.

Gasto anual de aceite de oliva en el convento de la Merced de Markina, 1630-1644

\begin{tabular}{|c|c|c|c|}
\hline PERIODO & $\begin{array}{c}\text { Alimentación } \\
\%\end{array}$ & $\begin{array}{c}\text { Iluminación } \\
\%\end{array}$ & $\begin{array}{c}\text { Litros anuales } \\
\text { por monja } *\end{array}$ \\
\hline $1630-1634$ & 61,6 & 38,4 & 3,28 \\
\hline $1635-1639$ & 65,4 & 34,6 & 3,45 \\
\hline $1640-1644$ & 61,2 & 38,8 & 4,48 \\
\hline
\end{tabular}

Elaboración propia. AMMB-AM Libros de gastos y de recibos.

*Se ha estimado que 1 libra equivale a 0,453 kilos y que 1 litro de aceite pesa 0,91 kilos, ya que la densidad del aceite es menor que la del agua.

Teniendo en cuenta este prorrateo, se ha procedido a estimar el porcentaje de aceite utilizado para alimentación o luminaria, considerando el progresivo incremento en el consumo de otros productos oleosos como velas de cera, sebo o aceite de ballena. Se ha supuesto que, aproximadamente hasta 1740, el aceite destinado a para alimentación mantenía una proporcionalidad similar a la de 1630-1644, pero se ha corregido con la variación del número de monjas en medias móviles de 10 años. Esta proporción se ha aplicado al total de aceite consumido para establecer las 
cantidades utilizadas en alimentación e iluminación, respectivamente ${ }^{42}$. Los resultados son elocuentes: el porcentaje destinado a aceite de mesa fue incrementándose a partir de la segunda mitad del siglo XVII como consecuencia de la sustitución paulatina de las lámparas de aceite por las velas de sebo y a partir de 1668, por el aceite de ballena mucho más competitivo en precio ${ }^{43}$.

Aun siendo evidente el incremento del uso de aceite de oliva en la dieta, no será hasta la segunda mitad del siglo XVIII cuando el convento se acerque a los 5 litros anuales por persona (incluyendo las luminarias) que se calculan para Madrid (Ringrose, 1985:148) o la localidad palentina de Astudillo (Hernández 2007:78). Todos ellos quedan lejos de los 5,2 litros de consumo exclusivamente alimenticio que cifra Allen (2001:421) para Europa antes de la sustitución del aceite por la mantequilla. Se puede afirmar, que el aceite se reservó para determinados momentos del año o comidas especiales y que, a pesar de un incremento sustancial de su utilización en el siglo XVIII, la grasa animal siguió siendo la más utilizada en las cocinas de la vertiente cantábrica ${ }^{44}$.

\subsection{Condimentos, especias, dulces y coloniales}

Junto a los alimentos básicos, el convento se abastecía de otros productos vinculados a un alto poder adquisitivo, con la única salvedad de la sal que se utilizaba para la conservación de alimentos y la elaboración de embutidos. Entre estos se encuentran el vinagre, especias - pimienta, pimentón, azafrán, clavo, anís -, frutos secos - orejones, ciruelas, nueces, pasas y almendras - , dulces - canela y azúcar, chocolate, rosquillas - , lácteos - leche y queso - y productos de huerta - ajos, cebollas, simientes, berza - . Como se puede ver, el convento de Markina estuvo muy lejos de ofrecer la variedad de especias y dulces que se registraron en los conventos andaluces (Gómez Navarro y Villegas, 2015: 99-107) o catalanes (Gras, 1996).

En líneas generales, se puede afirmar que este tipo de alimentos entraron a formar parte de la compra cotidiana del convento durante el siglo XVIII, especialmente

42. A partir de 1740 , la ratio empleada no difiere demasiado de la ofrecida para Madrid por LLopis y GarcíaMontero (2011:298).

43. Entre 1685-1709, el promedio del aceite de ballena era de 1,14 reales por libra frente a los 1,29 de la libra de sebo o los 1,67 de la de aceite. A partir de la segunda mitad del Setecientos, el uso de la cera gana posiciones frente a las lámparas de sebo o aceite. Se trata de un cambio cualitativo con el que se escenificaba una posición de preeminencia social, especialmente si se tiene en cuenta que el precio de la cera se duplicó en las últimas décadas del siglo.

44. González-Mariscal (2015:15) refleja una realidad muy diferente en el sur de la Península donde los sevillanos de finales del Quinientos consumían un promedio de 7 litros al año. También quedan lejos del consumo de otras instituciones eclesiásticas que rondan los 13,2 litros anuales en el siglo XVIII (Eirás, 1993: 43). 
en su segunda mitad (Tabla 10). Hasta entonces, el desembolso mayoritario iba destinado a la adquisición de sal para conservación de la matanza, acompañado por la compra muy ocasional de especias, queso, pasas y simientes para la huerta. A lo largo del último tercio del Seiscientos, las cocinas del convento incorporaron de manera regular pimienta, azafrán, ajos y cebollas, lo que nos habla de una mayor condimentación de los alimentos.

Tabla 10.

Promedio de gasto anual por monja en condimentos, especias y coloniales

Convento de la Merced de Markina, 1585- 1824 (en rsv)

\begin{tabular}{|c|c|c|c|c|c|c|c|c|c|}
\hline & Sal & Vinagre & Pimienta & Especias & $\begin{array}{c}\text { Frutos } \\
\text { secos }\end{array}$ & Dulces & Lácteos & Huerta & Total \\
\hline $1585-1624$ & 0,04 & - & - & 0,03 & 0,002 & - & - & 0,01 & 0,08 \\
\hline $1625-1654$ & 1,86 & - & - & - & - & - & 0,01 & 0,09 & 1,96 \\
\hline $1655-1704$ & 2,71 & - & 0,34 & 0,07 & - & - & - & 0,11 & 3,19 \\
\hline $1705-1754$ & 2,46 & 0,09 & 0,70 & 0,75 & 0,01 & 1,66 & 0,30 & 0,30 & 6,26 \\
\hline $1755-1794$ & 4,36 & 0,09 & 0,12 & 3,15 & 0,01 & 11,61 & 0,09 & 0,35 & 19,77 \\
\hline $1795-1824$ & 5,13 & - & - & 0,46 & - & 5,01 & 0,06 & 0,02 & 10,68 \\
\hline
\end{tabular}

Elaboración propia. AMMB-AM Libros de gastos y de recibos.

Sin embargo, es en el Setecientos cuando se produce la incorporación de productos nuevos, propios de personas con un alto nivel adquisitivo y habituales en las despensas de la mayoría de los conventos españoles. Clavo, canela, azúcar, chocolate y frutos secos estuvieron vinculados al «arbitro de los bizcochos» con el que los provinciales quisieron aliviar «sus necesidades advirtiendo que la mitad del producto fuese para la comunidad con el fin de que los viernes se le diera algo a la comunidad como día de ayuno» ${ }^{45}$. La comendadora de Markina ordenó comprar gallinas, cedazos, moldes y todos los ingredientes necesarios para su elaboración - azúcar, canela, anís y chocolate-. Aunque al principio la iniciativa tuvo una buena acogida en el pueblo, pronto se tornó claramente deficitaria por lo que esta actividad se abandonó a partir de 1769. De esta experiencia quedó el consumo regular de azúcar y canela, para la elaboración de arroz con leche, y de chocolate.

El chocolate, es uno de los alimentos que mayor presencia tuvo en las mesas de las clases privilegiadas, especialmente en las del clero ${ }^{46}$. En un principio, su ingesta se

45. Bérriz 1726. Libro de visitas canónicas [ES/AMMB/, F008.159 (0023/001-00)].

46. Sobre las implicaciones sociales y culturales del consumo de chocolate véase el trabajo de Norton, 2006. 
consideró contraria a la norma y, en consecuencia, restringida o prohibida en algunas comunidades (Gras, 1996:213-215 y Gómez Díaz, 2001: 392-393). A pesar de esto, su consumo consiguió popularizarse en todos los conventos en la segunda mitad del siglo XVIII. Como se ha explicado, en Markina se introdujo como ingrediente para la elaboración de los bizcochos, aunque reservaban una parte para beberlo como infusión, siguiendo el gusto de la época. Una vez que se abandonó la venta de repostería, las compras se limitaron a abastecer la demanda del claustro, con una ratio de gasto de 2,4 reales anuales por monja, un 82 por 100 menos que en el periodo anterior. Al parecer, en la década de 1780-89 se produjo una nueva reactivación de su consumo ya que el desembolso por este concepto se incrementó hasta los 11,7 reales anuales por monja. No duraría mucho. El inicio del periodo bélico, el incremento de la presión fiscal y la reducción de los ingresos provocaron una reducción en el abasto de los productos «lujosos» con la consiguiente reducción en todas las partidas.

\section{CONCLUSIONES}

En la segunda mitad del siglo XVIII, la estructura de gasto alimenticio del convento de la Merced de Markina comparte características propias de las instituciones religiosas del norte peninsular: pan, aceite de oliva, pescado fresco, huevos, especies o frutos secos (Real Sociedad Bascongada de Amigos del País, 1803:330-337), aunque bajo unos parámetros que podríamos calificar de austeros en lo que respecta a la cantidad y variedad de los bienes adquiridos.

Las monjas ajustaron la compra de alimentos a sus posibilidades económicas, a su número y a las posibilidades de aprovisionamiento de determinados productos en un entorno rural, pudiéndose diferenciar cuatro etapas con características propias. En la primera, que abarca desde su independencia de la casa Bidarte hasta aproximadamente 1670, el convento tuvo que hacer frente a un número creciente de vocaciones mientras se consolidaba económicamente, por lo que el cálculo de su umbral de gasto se realizaba sobre una cantidad fija por monja. Por ello, llevaron a cabo una gestión muy conservadora en la compra de alimentos con cierta tendencia al auto abastecimiento y un predominio de la salazón, tanto en carnes como en pescado. La compra de trigo para elaborar pan se llevó la mayor parte del desembolso completado con legumbres - haba y garbanzos - que se aderezaban con tocino o cecina procedentes de la matanza. En las vigilias, cumplían con aceite, sardina y bacalao, mientras que el carnero estaba destinado únicamente para las enfermas. Este patrón alimenticio estaba en consonancia con el que predominaba en el área rural cantábrica y, estaba más cercano al de sus convecinos que al de otros conventos situados en otras regiones españolas, en los que se puede observar mayor variedad de especies y la presencia de especias, dulces o aves. A partir de la década de 1670, a pesar de las dificultades económicas derivadas de la inflación y la pérdida

Ediciones Universidad de Salamanca / అ@@ Stud. his., H. ${ }^{a}$ mod., 41, n. 2 (2019), pp. 303-338 
de rentabilidad de los censos, el convento consiguió elevar su umbral de gasto gracias a la reducción del número de monjas. Se siguió realizando un cálculo diario individualizado, pero complementado con la compra de suplementos, especialmente en el caso pan. Poco a poco, los alimentos frescos fueron desplazando a la salazón, tanto en carnes como en pescados; se inició la ingesta regular de huevos vinculados siempre al pescado fresco y al precepto de la abstinencia; la vaca se impuso al cerdo y el aceite de oliva empezó a sustituir a la manteca. También se observa un cambio en la forma de cocinarlos con la utilización de pimienta, azafrán, ajos y cebollas. Sin embargo, no sería hasta la década de 1740 cuando el convento experimentaría un fuerte incremento de sus ingresos derivados del arrendamiento de fincas rústicas y una menor dependencia de los réditos de los censos. Este mayor poder adquisitivo permitió incrementar el desembolso por monja y consolidar el consumo de carne de vaca y pescado frescos sobre la salazón. En este periodo la sidra es sustituida por el vino clarete navarro y pequeñas cantidades de vino dulce de Málaga a la vez que a la vez que el aceite de oliva iba ganando presencia en la mesa. También se incorporaron a la cesta de la compra productos propios de las clases privilegiadas como especias, azúcar o chocolate, aunque fueran utilizados para elaborar bizcochos destinados a su venta. La contabilidad también registra el uso de nuevos útiles domésticos como los cubiertos, manteles, vasos de cristal, jarras de porcelana e incluso relojes que vienen a confirmar el cambio de cultura material que se está produciendo en toda Europa y de la que es partícipe el convento ${ }^{47}$. Esta etapa de prosperidad se prolongaría hasta la década de 1780 en que empieza a hacerse evidente el cambio de coyuntura económica. La situación se agravaría con la llegada de sus hermanas de Bilbao huyendo de la guerra y que originó que el número de religiosas casi se duplicara. Esta situación originó un nuevo reajuste del gasto que quedó limitado a los productos básicos de menor precio, la utilización del trigo procedente de sus arriendos para el abastecimiento de pan, y un repunte del consumo de alimentos en salazón.

\section{BIBLIOGRAFÍA}

ALBALÁ, K. (2012). Food for healing: Convalescent cookery in the early modern era. Studies in History and Philosophy of Biological and Biomedical Sciences, 43:323-328. bttps://doi.org/10.1016/j.shpsc.2011.10.024.

ALLEN, R. y ALBALÁ, K. (2003). Food in Early Modern Europe. Food Through History. London: Greenwood Press.

47. La bibliografía sobre este punto es amplísima. Braudel (1979) fue de los primeros en analizar los cambios en las pautas de consumo de los objetos cotidianos y, más recientemente, De Vries $(1993,1994,2006)$ ha iniciado toda una corriente historiográfica en la que el incremento de la demanda se identifica como paso previo hacia el crecimiento económico moderno.

Ediciones Universidad de Salamanca / అ@@ Stud. his., H. ${ }^{a}$ mod., 41, n. 2 (2019), pp. 303-338 
ALLEN, R. (2001). The Great Divergence in European Wages and Prices from the Middle Ages to the First World War. Explorations in Economic History 38, 411-447.

ANDRÉS UCENDO, J.I. y LANZA GARCÍA, R. (2012). El abasto del pan en el Madrid del siglo XVII. Studia Historica. Historia Moderna, 34, 59-95.

ANDRÉS UCENDO, J.I. y LANZA GARCÍA, R. (2014). Prices and Real Wages in Seventeenth-Century Madrid. The Economic History Review, 67 (3), 607-626. doi: dx.doi.org/10.1111/1468-0289.12047.

ATIENZA LÓPEZ, Á. (1991). Transformaciones en el sistema de crédito y crisis de las economías monásticas a fines del Antiguo Régimen en Aragón. Revista de Historia Económica-Journal of Iberian and Latin American Economic History, 9 (3), 499-511.

BERNARDOS SANZ, J.U. (2004 a). El consumo en España (1750-1850). En: LLopis (ed.), El legado económico del Antiguo Régimen en España. Barcelona: Crítica, 273-300.

BERNARDOS SANZ, J.U. (2004b). La evolución de los sistemas de abastecimiento y el consumo de alimentos y otros productos básicos a finales del Antiguo Régimen. Trabajo presentado en el II Congreso de Historia Económica. La Historia Económica hoy, entre la Economía y la Historia, México D.F.

BRAUDEL, F. (1979). Civilisation matérielle, économie, capitalismo, XVe-XVIIIe siècle. Les structures du quotidien: le impossible et le impossible. Tome I. Paris: Colin.

BURGO LÓPEZ, M. ${ }^{a}$ C. (1987). El consumo alimenticio del clero regular femenino en el Antiguo Régimen: el ejemplo del monasterio de San Payo de Antealtares. Studia Historica: Historia Moderna, 5 (1), 221-240. .

CALDERÓN, A.; GARCÍA-MONTERO, H. y LLOPIS, E. (2017). New research guidlines for living standars, consumer baskets, and prices in Madrid and Mexico.

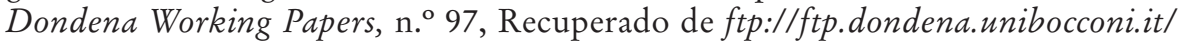
WorkingPapers/Dondena_WP097.pdf .

CARRIÓN, I. (1996). Los antiguos pesos y medidas guipuzcoanos, Vasconia, 24, 59-79.

CATALÁN MARTÍNEZ, E. (2009), El problema de la vivienda en Bilbao (1700-1815). En Rey, O. y López, R. (eds.), El mundo urbano en el siglo de la Ilustración. Tomo II, Santiago de Compostela: Xunta de Galicia, Santiago de Compostela, 83-99.

CEBALLOS, C. (2001). Arozas y Ferrones: las ferrerias de Cantabria en el Antiguo Régimen. Santander: Universidad de Cantabria.

CONSTITUCIONES (1624). Regla y Constituciones de las religiosas, y monjas del Sagrado orden de Ntra. Sra. de la Merced Redempción de Cautivos. Burgos. Biblioteca Nacional de España [BNE] sig. 66839.

CUBILLO DE LA PUENTE, R. (1998). El pescado en la alimentación de Castilla y León durante los siglos XVIII y XIX. León: Universidad de León.

DE VRIES, J. (1993). Between the purchasing power and the world of goods: Understanding the household economy in the Early Modern Europe. En Brewer, J., Porter, R. (eds.). Consumption and the world of goods. Nueva York: Routledge, 85-132.

DE VRIES, J. (1994). The Industrial Revolution and The Industrious Revolution, The Journal of Economic History, 54 (2), 249-270.

Ediciones Universidad de Salamanca / @®@@ Stud. his., H. ${ }^{a}$ mod., 41, n. 2 (2019), pp. 303-338 
DE VRIES, J. (2006). The Industrious Revolution and Economic Growth, 1650-1830. En Paul A. David \& Mark Thomas (eds.), The Economic future in historical perspective, vol. 13. OUP/The British Academy, 43-71.

EIRÁS ROEL, A. (1974). La historia cuantitativa del consumo alimentario: estado actual de las investigaciones. Hispania, (XXXIV), 105-148.

EIRÁS ROEL, A. (1993). La Historia de la alimentación en la España moderna: resultados y problemas. Obradorio de Historia Moderna, 2, 35-64.

FAO (3 de mayo de 2017). Mejorando la nutrición a través de buertos y granjas familiares. La cría de cerdos. Recuperado de http://www.fao.org/docrep/V5290S/v5290s23.htm.

FELIÚ, G. (2004). Aproximació a un index del cost de la vida a Barcelona, 1501-1807 en AA. DD., Josep Fontana. Història i projecte social. Barcelona: Crítica. Barcelona, 151-170.

FERNÁNDEZ DE PINEDO, E. (1974). Crecimiento económico y transformaciones sociales del País Vasco. 1100-1850. Madrid: Siglo XXI.

FERNÁNDEZ DE PINEDO, E. (2015). El abastecimiento y consumo de carnes en Bilbao en el siglo XVII. En: Martínez Shaw, C., Tedde de Lorca, P., Tinoco, S. (coords.). Andalucía-España-Las Indias. Pasión por la Historia. Homenaje al profesor Antonio Miguel Bernal. Sevilla: Editorial de la Universidad de Sevilla-Marcial Pons, 295-309.

GENTILCORE, D. (2015). Food and Health in Early Modern Europe: Diet, Medicine and Society, 1450-1800. London: Bloomsbury.

GÓMEZ DÍAZ, D. (2001). «Buen alimento, mejor pensamiento»: el consumo en un convento almeriense a finales del s. XVII. Espacio, Tiempo y Forma, Serie IV, Historia Moderna, 14, 377-405.

GÓMEZ NAVARRO, M. ${ }^{a}$ S. (2010). Vida cotidiana de monjas y religiosas en la España Moderna a través de sus contabilidades. El convento cordobés de Santa Ana a fines del Antiguo Régimen. Revista de Historia Social y de las Mentalidades, 14 (2), 103-136.

GÓMEZ NAVARRO, M. ${ }^{a}$ S. y VILLEGAS BECERRIL, A. (2015). Entre los pucheros también anda Dios y (posible) mesa de las Carmelitas descalzas a fines del Antiguo Régimen según el convento cordobés de Santa Ana. En F.J. Campos y Fernández de Sevilla (coord.), Santa Teresa y el mundo teresiano del barroco. San Lorenzo del Escorial: Real Centro Universitario Escorial-María Cristina, 93-108.

GONZÁLEZ AGUDO, D. (2016). Prices in Toledo, sixteenth and seventeenth centuries». Trabajo presentado en el $41^{\text {st }}$. Annual Meeting of the social Science History Association. Chicago.

GONZÁLEZ-MARISCAL, M. (2015). Inflación y niveles de vida en Sevilla durante la Revolución de los Precios. Revista de Historia Económica/Journal of Iberian and Latin American Economic History, 33 (3). doi:10.1017/S0212610915000282.

GRAS I CASANOVAS, M.M. (1996). Cuerpo y alma en el carmelo descalzo femenino. Una aproximación a la alimentación conventual en la Cataluña moderna. Studia Historica. Historia Moderna, (14): 207-221.

HERNÁNDEZ GARCÍA, R. (2007). Abastecimiento y consumo de aceite de oliva a finales del Antiguo Régimen en una localidad industrial: Astudillo, 1779-1832. Investigaciones Históricas: Época Moderna y Contemporánea, 27, 77-94.

Ediciones Universidad de Salamanca / అ@@ Stud. his., H. ${ }^{a}$ mod., 41, n. 2 (2019), pp. 303-338 
INTXAUSTEGUI JAUREGI, N.J. (2018). La mujer religiosa en Bizkaia durante los siglos XVI-XVIII. Bilbao: Diputación Foral de Bizkaia.

KIPLE K.F. y ORNELAS, K. C. (eds.) (2000), The Cambridge World History of food, vol. 2. Cambridge: Cambridge University Press.

LANDI, F. (2004). Confische e svikuppo capitalistico. I grande patrimoni del clero regolare in Etá Moderna in Europa e en el Continente Americano. Milan: Franco Angeli.

LANGUE, J. y ZABALA, M. (2000). Aproximación a la contabilidad del convento de Santa Isabel de Areatza como indicativo de la coyuntura económica de Bizkaia (1680/1885). Brocar, 24, 19-47.

LANZA GARCÍA, R. (1991). La población y el Crecimiento Económico de Cantabria en el Antiguo Régimen. Madrid: Universidad Autónoma de Madrid. .

LIVI BACCI, M. (1988). Ensayo sobre la historia demográfica de Europa: población y alimentación en Europa. Barcelona: Ariel.

LLOPIS, E. y GARCÍA MONTERO, H. (2011). Precios y salarios en Madrid, 1680-1800. Investigaciones de Historia Económica-Economic History Research 7 (2), 295-309. doi:10.1016/j.ihe.2010.10.002.

LÓPEZ LOSA, E. y PIQUERO, S. (2016). Spanish wages in the North-Western European mirror, 1500-1800. On the timings and magnitude of the Little Divergence in Europe. Documentos de Trabajo de la AEHE, n. ${ }^{\circ}$ 1607. Recuperado de http://econpapers.repec. org/paper/abedtaehe/1607.htm.

LÓPEZ MARTÍNEZ, A. L. (1992). La economía de las órdenes religiosas en el antiguo Régimen: sus propiedades y rentas en el reino de Sevilla, Sevilla: Diputación Provincial.

LÓPEZ MARTÍNEZ, A. L. (1995). Mecanismos y formación del patrimonio del clero regular en el reino de Sevilla durante el Antiguo Régimen. Criterios que presidieron la adquisición de sus propiedades. En Actas del II Congreso de Historia de Andalucía. Andalucía Moderna (I), Córdoba: Publicaciones de la Consejería de cultura de la Junta de Andalucía y obra social y cultural Caja Sur, 453-461.

MARTÍNEZ LLOPIS, M. (1989), Historia de la gastronomía española. Madrid: Alianza editorial.

MONTANARI, M. (1993). El hambre y la abundancia. Historia y cultura de la alimentación en Europa. Barcelona: Crítica.

MONTANARI, M. y FLANDRIN, J.L. (1996). Histoire de l'alimentation. Paris: Fayard.

NORTON, M. (2006). Tasting Empire: Chocolate and the European Internalization of Mesoamerican Aesthetics. American Historical Review, 111(3), 660-691. DOI: 10.1086/ahr.111.3.660.

PALACIO ATARD, V. (1998). La alimentación de Madrid en el siglo XVIII y otros estudios madrileños. Madrid: Real Academia de la Historia.

PIQUERO, S. (2000). Alimentación, nutrición y salud en la Guipúzcoa del Antiguo Régimen. Unas consideraciones. Zainak, 20, 227-241.

REAL SOCIEDAD BASCONGADA DE AMIGOS DEL PAÍS (1768). Ensayo de la Sociedad Bascongada de los Amigos del País año 1766 dedicado al Rey N. Señor, Vitoria: Thomas de Robles.

Ediciones Universidad de Salamanca / అ@@ Stud. his., H. ${ }^{a}$ mod., 41, n. 2 (2019), pp. 303-338 
REAL SOCIEDAD BASCONGADA DE AMIGOS DEL PAÍS (1803). Curiosidades Históricas de las Provincias Bascongadas. Año 1803. Noticia sobre la economía doméstica de los Labradores en varios pueblos. Euskal-Erria. Revista Bascongada, 44 (1ºm. 1901), 330-337, 359-364. .

RINGROSE, D.R. (1985). Madrid y la economía española, 1560-1850. Madrid: Alianza Universidad.

RUANO, A. y ALBERDI, X. (2006). ...LLeben... las colas a las varrigas de los bufos...: Balleneros guipuzcoanos en las matanzas de ballenas de Galicia y Asturias durante los siglos XVI y XVII, Obradoiro de Historia Moderna, (15), 77-111.

SARTI, R. (2003). Vida en familia. Casa, comida y vestido en la Europa Moderna. Barcelona: Crítica.

SORIANO TRIGUERO, C. (1994). Los modos de subsistencia clarianos. Las fuentes de ingresos del convento de Santa Clara de Madrid (siglos XVII-XVIII). Archivo Iberoamericano, (213-214), 545-566.

SORIANO TRIGUERO, C. (2000), La propiedad inmobiliaria de los conventos femeninos madrileños en el siglo XVIII. Cuadernos de Historia Moderna, 24, 11-31.

URIARTE AYO, R. (1988). Estructura, Desarrollo y crisis de la siderurgia tradicional vizcaina (1700-1840), Bilbao: Universidad del País Vasco.

Ediciones Universidad de Salamanca / 요 Stud. his., H. ${ }^{a}$ mod., 41, n. 2 (2019), pp. 303-338 
ELENA CATALÁN MARTÍNEZ

LAS COSAS DEL COMER. EVOLUCIÓN DEL GASTO ALIMENTICIO

EN UN CONVENTO RURAL DE BIZKAIA, (1585-1825)

ANEXO I.

Composición porcentual del gasto cotidiano en el convento de mercedarias de Markina (1584-1825)

\begin{tabular}{|c|c|c|c|c|c|c|}
\hline & $\begin{array}{l}1585 \\
1624 \\
\end{array}$ & $\begin{array}{l}1625 \\
1654 \\
\end{array}$ & $\begin{array}{l}1655 \\
1704 \\
\end{array}$ & $\begin{array}{l}1705 \\
1754\end{array}$ & $\begin{array}{l}1755 \\
1794 \\
\end{array}$ & $\begin{array}{l}1795 \\
1824\end{array}$ \\
\hline ALIMENTACION & 91,6 & 74,6 & 87,7 & 79,0 & 70,3 & 57,2 \\
\hline Pan/trigo & 85,2 & 69,2 & 59,7 & 54,4 & 43,7 & 22,6 \\
\hline Carne & 5,8 & 18,7 & 23,2 & 18,1 & 28,3 & 40,4 \\
\hline Pescado & 0,3 & 3,3 & 6,6 & 7,2 & 7,6 & 7,5 \\
\hline Aceite de oliva & 0,1 & 1,5 & 3,9 & 6,0 & 5,9 & 9,1 \\
\hline Sidra & 8,0 & 5,0 & 4,7 & 5,4 & 0,2 & - \\
\hline Vino & 0,3 & 0,02 & - & 4,5 & 9,3 & 14,5 \\
\hline Legumbre alimento & 0,1 & 0,4 & 0,3 & 1,3 & 1,1 & 0,7 \\
\hline Alimento ganado & 0,2 & 0,6 & 0,5 & 0,6 & 0,7 & 1,8 \\
\hline Leche y huevos & - & 0,01 & - & 0,1 & 0,02 & 0,02 \\
\hline Pimienta & - & - & 0,1 & 0,3 & 0,02 & - \\
\hline especias & 0,03 & - & 0,02 & 0,3 & 0,5 & 0,1 \\
\hline Sal & 0,2 & 1,2 & 1,0 & 1,0 & 0,7 & 1,6 \\
\hline Frutos secos & 0,002 & - & - & 0,01 & 0,002 & - \\
\hline Chocolate & - & - & - & 0,7 & 2,0 & 1,7 \\
\hline Fruta, hortalizas y simientes & 0,01 & 0,1 & 0,04 & 0,1 & 0,1 & 0,01 \\
\hline COMBUSTIBLE E ILUMINACION & 0,5 & 1,1 & 8,8 & 6,0 & 6,0 & 11,1 \\
\hline Cera & 12,0 & 8,2 & 1,0 & 4,9 & 20,7 & 34,0 \\
\hline Sebo & 10,7 & 2,6 & 8,5 & 9,0 & 9,0 & 2,5 \\
\hline Aceite Oliva & 4,2 & 51,4 & 15,9 & 12,4 & 10,8 & 5,5 \\
\hline Aceite Ballena & - & 0,2 & 0,8 & 1,1 & - & - \\
\hline Cirios & - & 8,2 & 0,7 & 4,2 & 4,9 & 0,6 \\
\hline Carbón vegetal & - & - & 0,7 & 1,1 & 7,3 & 24,2 \\
\hline Cisco & - & - & - & 0,01 & 0,7 & 0,02 \\
\hline Leña & 73,0 & 29,4 & 72,5 & 67,2 & 46,6 & 33,3 \\
\hline VIVIENDA & 3,6 & 21,4 & 4,2 & 2,6 & 14,9 & 19,1 \\
\hline TEXTIL & 0,3 & 0,1 & 0,1 & 1,2 & 0,6 & 0,3 \\
\hline Ropa de cama & 14,5 & - & 10,4 & 10,8 & 23,0 & 13,2 \\
\hline Ropa de mesa & 61,3 & 2,0 & 11,3 & 21,6 & 20,2 & 27,0 \\
\hline Ropa personal & 19,3 & 43,9 & 46,9 & 0,5 & - & - \\
\hline Tejidos y fornituras & 2,0 & 2,2 & - & 21,7 & 25,3 & 49,7 \\
\hline Ajuar iglesia y culto & 2,8 & 51,9 & 31,4 & 45,4 & 31,5 & 10,1 \\
\hline MENAJE & 0,4 & 1,0 & 1,7 & 1,7 & 1,5 & 5,4 \\
\hline Muebles & 19,1 & 27,1 & 14,5 & 2,6 & 10,2 & 7,7 \\
\hline Menaje cocina & 47,7 & 71,4 & 60,9 & 55,8 & 52,4 & 29,9 \\
\hline Almacenaje & 15,6 & 1,4 & 10,3 & 4,2 & 5,9 & 8,6 \\
\hline Útiles limpieza & 5,1 & - & 3,8 & 8,9 & 15,9 & 0,7 \\
\hline Varios & 12,4 & - & 10,5 & 28,6 & 15,7 & 53,1 \\
\hline SERVICIOS & 3,4 & 1,7 & 2,5 & 9,4 & 6,7 & 6,9 \\
\hline Cirujano & - & 15,1 & 33,3 & 18,8 & 18,2 & 22,2 \\
\hline Médico & - & - & - & 27,2 & 28,9 & 32,1 \\
\hline Botica & 0,5 & 1,1 & 15,0 & 25,4 & 30,8 & 18,0 \\
\hline Lavandería & - & - & 1,2 & 2,9 & 0,4 & 2,9 \\
\hline Criadas & 99,5 & 83,9 & 50,5 & 25,7 & 21,8 & 24,9 \\
\hline TOTAL GASTO COTIDIANO & 89,2 & 86,9 & 77,0 & 62,4 & 66,6 & 63,9 \\
\hline TOTAL CULTO & 4,9 & 2,9 & 13,5 & 15,9 & 8,4 & 7,2 \\
\hline TOTAL ADMINISTRACIÓN & 5,9 & 10,2 & 9,5 & 21,7 & 25,0 & 28,9 \\
\hline
\end{tabular}

Fuente: Elaboración propia. AMMB-AM Libros de gastos y de recibos.

Ediciones Universidad de Salamanca / @®@@ Stud. his., H. ${ }^{a}$ mod., 41, n. 2 (2019), pp. 303-338 